This item was submitted to Loughborough's Research Repository by the author.

Items in Figshare are protected by copyright, with all rights reserved, unless otherwise indicated.

\title{
Microfluidic production of poly(1,6-hexanediol diacrylate)-based polymer microspheres and bifunctional microcapsules with embedded TiO2 nanoparticles
}

\section{PLEASE CITE THE PUBLISHED VERSION}

https://doi.org/10.1021/acs.langmuir.8b02452

\section{PUBLISHER}

(c) American Chemical Society

\section{VERSION}

AM (Accepted Manuscript)

\section{PUBLISHER STATEMENT}

This document is the Accepted Manuscript version of a Published Work that appeared in final form in Langmuir, copyright $\odot$ American Chemical Society after peer review and technical editing by the publisher. To access the final edited and published work see https://pubs.acs.org/doi/10.1021/acs.langmuir.8b02452.

\section{LICENCE}

CC BY-NC-ND 4.0

\section{REPOSITORY RECORD}

Nuumani, Ruqaya Al, Guido Bolognesi, and Goran Vladisavljevic. 2018. "Microfluidic Production of Poly(1,6hexanediol Diacrylate)-based Polymer Microspheres and Bifunctional Microcapsules with Embedded Tio2 Nanoparticles". figshare. https://hdl.handle.net/2134/34873. 


\title{
Microfluidic production of poly(1,6-hexanediol
}

\author{
diacrylate)-based polymer microspheres and
}

\section{bifunctional microcapsules with embedded $\mathrm{TiO}_{2}$}

\author{
nanoparticles
}

Ruqaiya Al nuumani, Guido Bolognesi, Goran T. Vladisavljević*

Department of Chemical Engineering, Loughborough University, Loughborough LE11 3TU, United Kingdom.

Keywords: Composite Inorganic-Organic Polymer; Immobilised $\mathrm{TiO}_{2}$; Photocatalysis; CoreShell Microcapsules; Photopolymerisation; Microencapsulation.

Published in Langmuir 


\section{Abstract}

Application of $\mathrm{TiO}_{2}$ as a photocatalyst and UV protector is restricted by the difficulties in the recovery of $\mathrm{TiO}_{2}$ nanoparticles after water treatment. In this work, $\mathrm{TiO}_{2}$ nanoparticles (Degussa P25) were immobilised within easily recoverable poly(1,6-hexanediol diacrylate)-based polymer microspheres produced by on-the-fly photopolymerisation of microfluidically generated droplets. Due to fast polymerisation reaction, $\mathrm{TiO}_{2}$ was uniformly distributed within the polymer network. The transformation of double bonds in terminal vinyl groups of 1,6-hexanediol diacrylate (HDDA) monomer into single bonds during photopolymerisation was confirmed by Fourier Transform infrared spectroscopy. The microspheres containing $0.5 \mathrm{wt} \% \mathrm{TiO}_{2}$ embedded in a poly(HDDA) matrix degraded $80 \%$ of methylene blue from $1 \mathrm{ppm}$ aqueous solution in $9 \mathrm{~h}$ under UV light irradiation at $365 \mathrm{~nm}$. The microspheres could easily be separated from water and used in repeated cycles without any loss in photocatalytic activity. The inclusion of $\mathrm{TiO}_{2}$ within a polymer matrix increased the thermal degradation temperature of the material from 364 to 389 ${ }^{\circ} \mathrm{C}$. Bifunctional microcapsules consisted of aqueous or liquid paraffin core enclosed within a $\mathrm{TiO}_{2} /$ poly(HDDA) composite polymer shell were also prepared. The fluorescent dye calcein was encapsulated in the core with $100 \%$ efficiency.

\section{Introduction}

Incorporation of inorganic nanoparticles (e.g. $\mathrm{TiO}_{2}, \mathrm{Fe}_{2} \mathrm{O}_{3}, \mathrm{SiO}_{2}$, etc) into polymer matrix can significantly improve the mechanical, optical, electrical, magnetic, and barrier properties of the 
host polymer. ${ }^{1-5}$ The synergistic effects between nanofillers and support polymer have been exploited in photovoltaic applications, ${ }^{6}$ catalysis, ${ }^{7}$ food packaging, ${ }^{8}$ advanced imaging, ${ }^{9}$ and controlled drug delivery. ${ }^{10,11}$

$\mathrm{TiO}_{2}$ is a chemically stable, cheap, non-toxic material with exceptional photocatalytic activity $^{12-14}$, antibacterial and optical properties, ${ }^{15,16}$ and high UV protection capability, ${ }^{12,13,17,18}$ widely used as a pigment, catalyst, antimicrobial agent, and UV-blocker in paints and coatings, ${ }^{19}$ electrophoretic displays,${ }^{20}$ packaging films, ${ }^{21}$ sunscreens, ${ }^{22}$ and biosensors. ${ }^{14,15,19,23}$ When irradiated with UV light, $\mathrm{TiO}_{2}$ is able to mineralize organic compounds from aqueous solutions and produce hydrogen. ${ }^{24-26}$ However, $\mathrm{TiO}_{2}$ nanoparticles are difficult to separate from aqueous dispersions after photocatalysis. Immobilising $\mathrm{TiO}_{2}$ on solid microparticles is an attractive strategy to achieve easy particle separation ${ }^{27}$ and prevent ecotoxicological risks associated with residual $\mathrm{TiO}_{2}$ in water. ${ }^{28}$ To minimise separation costs, support particles should be large, but with increasing the particle size, $\mathrm{TiO}_{2}$ becomes less accessible to photons and the internal mass transfer resistance becomes increasingly more dominant, limiting diffusion to/from the surface of $\mathrm{TiO}_{2}$ nanoparticles. Thus, ideally $\mathrm{TiO}_{2}$ should be embedded only within a thin surface layer of support material. The inclusion of $\mathrm{TiO}_{2}$ within polymer matrix can also improve encapsulation efficiency of active ingredients entrapped within the polymer matrix as $\mathrm{TiO}_{2}$ nanoparticles can act as a porosity modifier and reduce the mesh size of the polymer network. $\mathrm{TiO}_{2}$ nanoparticles can also act as physical obstacles to diffusing molecules, leading to their more tortuous pathway through the polymer matrix, which is known as the tortuosity effect". ${ }^{29}$

The common techniques for the incorporation of $\mathrm{TiO}_{2}$ into polymer microspheres are dispersion polymerisation, ${ }^{20}$ mini-emulsion polymerisation, ${ }^{30}$ emulsion polymerisation, ${ }^{31}$ and suspension polymerisation in stirred tank reactors. ${ }^{32}$ The disadvantages of these methods are the 
lack of control over the size and morphology of microspheres and low encapsulation efficiency of $\mathrm{TiO}_{2}(60-80 \%)$, due to long polymerisation time and non-uniform shear in stirred vessels..$^{30,31}$ More uniform microspheres with a coefficient of variation $(C V)$ of particle sizes of 10-20\% were produced using Shirasu Porous Glass (SPG) membrane emulsification and subsequent suspension polymerisation ${ }^{33}$ or solvent evaporation, ${ }^{34}$ but SPG membrane is prone to clogging by $\mathrm{TiO}_{2}$, due to its highly interconnected and tortuous pores. Microfluidic strategies for generation of polymer/ $\mathrm{TiO}_{2}$ particles have also been developed, often based on suspension polymerization or solvent evaporation combined with in situ synthesis of $\mathrm{TiO}_{2}$ by hydrolysis of organotitanium compounds. ${ }^{35,36}$

In this work, novel $\mathrm{TiO}_{2} /$ poly(1,6-hexanediol diacrylate)-based polymer microspheres and microcapsules with $C V<2 \%$ were prepared by microfluidic emulsification and 'on the fly' photopolymerisation of various template emulsions including (solid-in-oil)-in-water ((S/O)/W), water-in-(solid-in-oil)-in-water $\left(\mathrm{W}_{1} /(\mathrm{S} / \mathrm{O}) / \mathrm{W}_{2}\right)$, and oil-in-(solid-in-oil)-in-water $\left(\mathrm{O}_{1} /\left(\mathrm{S} / \mathrm{O}_{2}\right) / \mathrm{W}\right)$. Multiple emulsion drops were generated by one-step pinch-off of a compound jet by co-flow combined with counter-current flow focusing, ${ }^{37,38}$ which allows more facile control over the shell thickness than two separate pinch-off events in traditional planar flow focusing devices. ${ }^{39,40}$ Novel composite polymer capsules can be used for encapsulation of photolabile and volatile materials, which can be released by applying pressure or friction, but also in thermal energy storage, ${ }^{41}$ biosensing, ${ }^{42}$ electronic displays, ${ }^{43}$ photonics,${ }^{44}$ inertial confinement fusion,${ }^{45}$ and solvent extraction. ${ }^{46}$ Conventional methods for the fabrication of these capsules such as internal phase separation, complex coacervation, layer-by-layer electrostatic deposition, and thermallyinduced polymerisation processes are more time consuming, require multiple processing steps, and the shell thickness is more difficult to control. 
The entrapment efficiency of $\mathrm{TiO}_{2}$ in the host polymer was $100 \%$ due to short curing time of just several seconds, as compared to several hours in thermally initiated polymerisation processes. $^{47}$ The entrapment efficiency of encapsulated hydrophilic dye was also $100 \%$ due to the complete separation of two aqueous streams during multiple drop formation. The method allows to control accurately and independently the size of the microcapsules, the shell thickness, which can be below $10 \mu \mathrm{m}$, and the number of cores, which can range between one and six.

\section{Experimental}

\section{Materials}

$\mathrm{TiO}_{2}$ nanoparticles (Degussa p25) with a mean size of $20 \mathrm{~nm}$ and a rutile/anatase ratio of 85/15 were used as a photocatalyst. 1,6 Hexanediol diacrylate (HDDA, Sigma-Aldrich) and 2-hydroxy2-methylpropiophenone (Darocur 1173, Sigma-Aldrich) were used as a UV-curable monomer and photoinitiator, respectively. Glycerol (Sigma-Aldrich) and poly(vinyl alcohol) (PVA, $\mathrm{M}_{\mathrm{w}}=$ 13,000-23,000, 87-89\% hydrolysed, Sigma-Aldrich) were used as the viscosity modifier and hydrophilic stabiliser, respectively. Polyglycerol polyricinoleate (GRINSTED ${ }^{\circledR}$ PGPR, Danisco) was used as an oil soluble stabiliser. Octadecyltrimethoxysilane (Sigma-Aldrich) and 2[methoxy(polyethyleneoxy)propyl]trimethoxysilane (Gelest, Inc.) were used for hydrophobic and hydrophilic modification of glass surface. Methylene blue (MB, 3,4-bis(dimethylamino)phenothiazine-5-thionium chloride, Sigma Aldrich) was used as a model contaminant. Ultrapure water was supplied using a Millipore Milli-Q Plus 185 water purification system. To finely disperse $\mathrm{TiO}_{2}$ in the oil phase, a mixture of $\mathrm{TiO}_{2}$ nanoparticles, Darocur 1173, and HDDA was sonicated for $30 \mathrm{~min}$. The dispersed phase in $(\mathrm{S} / \mathrm{O}) / \mathrm{W}$ emulsions was a mixture of $0.5 \mathrm{wt} \% \mathrm{TiO}_{2}$ and $1 \mathrm{wt} \%$ Darocur 1173 dissolved in HDDA. The middle fluid in double emulsions was a 
mixture of $3 \mathrm{wt} \%$ PGPR, $0.5 \mathrm{wt} \% \mathrm{TiO}_{2}$, and $1 \mathrm{wt} \%$ Darocur 1173 dissolved in HDDA. The content of $\mathrm{TiO}_{2}$ in the middle phase was relatively low to prevent aggregation of $\mathrm{TiO}_{2}$ nanoparticles and their deposition onto the walls of the capillaries. In some experiments, 1.25 ppm calcein (Bis[N,N-bis(carboxymethyl)aminomethyl]fluorescein, Sigma-Aldrich) and Nile Red (9-(diethylamino)benzo[a]phenoxazin-5-one, Sigma-Aldrich) were added in the inner and middle fluid respectively. Paraffin oil (Sigma-Aldrich) and $2 \mathrm{wt} \%$ aqueous PVA solution were used as the inner fluid in $\mathrm{O}_{1} /\left(\mathrm{S} / \mathrm{O}_{2}\right) / \mathrm{W}$ and $\mathrm{W}_{1} /(\mathrm{S} / \mathrm{O}) / \mathrm{W}_{2}$ emulsions, respectively. The outer fluid was a mixture of $4 \mathrm{wt} \%$ PVA and $40 \mathrm{wt} \%$ glycerol.

The physical properties of fluids used for the preparation of $\mathrm{W}_{1} /(\mathrm{S} / \mathrm{O}) / \mathrm{W}_{2}$ emulsion are listed in Table 1. The densities and viscosities were measured using the pycnometer method and a DISCOVERY HR-3 hybrid rheometer, respectively. The interfacial tensions were measured using a Krüss DSA-100S pendant drop tensiometer (KRÜSS GmbH, Hamburg, Germany).

Table 1. The composition and physical properties of liquids used to prepare $\mathrm{W}_{1} /(\mathrm{S} / \mathrm{O}) / \mathrm{W}_{2}$ emulsion.

\begin{tabular}{llll}
\hline & Inner phase (W) & Middle phase (S/O) & Outer phase (W2) \\
\hline & $\begin{array}{l}2 \mathrm{wt} \% \text { PVA in DI } \\
\text { water }\end{array}$ & $\begin{array}{l}0.5 \mathrm{wt} \% \mathrm{TiO}_{2}+ \\
1 \mathrm{wt} \% \text { Darocur } 1173 \\
+3 \mathrm{wt} \% \text { PGPR in } \\
\text { HDDA }\end{array}$ & $\begin{array}{l}4 \mathrm{wt} \% \mathrm{PVA}+ \\
40 \mathrm{wt} \% \text { glycerol } \\
\text { in DI water }\end{array}$ \\
\hline $\begin{array}{l}\text { Density at } 298 \mathrm{~K} \\
\left(\mathrm{~kg} / \mathrm{m}^{3}\right)\end{array}$ & 1080 & 1010 & 1100 \\
\hline $\begin{array}{l}\text { Viscosity at } 298 \mathrm{~K} \\
(\mathrm{mPa})\end{array}$ & 1.61 & 6.5 & 20.9 \\
\hline $\begin{array}{l}\text { Interfacial tension at } \\
\begin{array}{l}298 \mathrm{~K} \\
(\mathrm{mN} / \mathrm{m})\end{array}\end{array}$ & 6.1 & - & 3.4 \\
\hline
\end{tabular}

\section{Fabrication of glass capillary devices}


Devices were fabricated using round (I.D./O.D. $=0.58 / 1.00 \mathrm{~mm}$, Intracel, UK) and square (I.D. $=1.05 \pm 0.1 \mathrm{~mm}$, AIT Glass, Rockaway, USA) borosilicate glass capillaries according to a standard protocol. ${ }^{37}$ Briefly, the capillaries were assembled on a microscope slide and connected to inlet tubing via hypodermic needles (Fig. 1). Round capillaries were pulled using the P-97 micropipette puller (Sutter Instrument Co., UK), polished with abrasive paper to the desired orifice size, and dip-coated with a silane solution. A hydrophobic and hydrophilic coating was applied for the injection and collection tube, respectively. The capillaries and needles were fixed in place using a Devcon ${ }^{\circledR} 5$-min epoxy.

\section{Experimental setup and procedure}

Microspheres were produced by counter-current flow focusing (Fig. 1(a)) and microcapsules were prepared by co-flow combined with counter-current flow focusing (Fig. 1 (b)). The fluids were supplied from gas-tight glass syringes (VWR Catalyst Company, UK) using Harvard Apparatus 11 Elite syringe pumps and polyethylene medical tubing $(0.86 \mathrm{~mm}$ I.D. and $1.52 \mathrm{~mm}$ O.D, Fisher Scientific, UK). A GXMXDS-3 inverted biological microscope and Phantom V5.1 high-speed camera interfaced to a PC computer were used to observe the drop formation. The videos were analyzed using ImageJ v.1.44 programme (Wayne Rasband, National Institute of Health) to determine droplet diameters, shell thickness and generation frequency. 


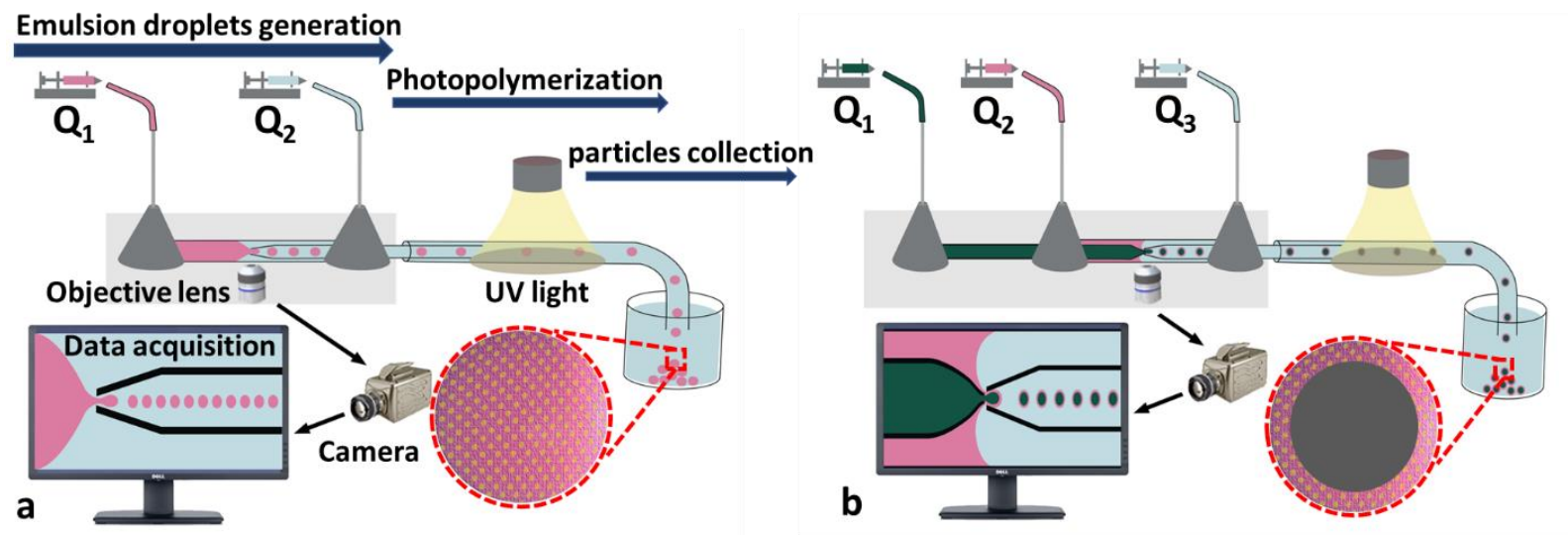

Figure 1. The experimental setup consisting of glass capillary devices, syringe pumps, inverted microscope, high-speed camera, and a UV-A light source: (a) 2-phase device with two pumps for producing $(\mathrm{S} / \mathrm{O}) / \mathrm{W}$ emulsion. $Q_{1}$ and $Q_{2}$ are the dispersed phase $(\mathrm{S} / \mathrm{O})$ and continuous phase $(\mathrm{W})$ flow rates respectively; (b) 3-phase device with three pumps for producing $\mathrm{W}_{1} /(\mathrm{S} / \mathrm{O}) / \mathrm{W}_{2}$ emulsion. $Q_{1}, Q_{2}, Q_{3}$ are the inner phase $\left(\mathrm{W}_{1}\right)$, middle phase $(\mathrm{S} / \mathrm{O})$, and outer phase $\left(\mathrm{W}_{2}\right)$ flow rates, respectively.

The droplets were exposed to UV-A radiation of $0.004 \mathrm{~mW} / \mathrm{cm}^{2}$ in the collection tube. All parts of the setup except the collection tube were covered by aluminum foil to prevent the premature polymerisation of HDDA. The first step in the polymerisation of HDDA is a UVlight-induced homolytic cleavage of the $\mathrm{C}-\mathrm{C}$ bond between the carbonyl group and the aliphatic carbon of the initiator molecule (Fig. 2a) and the formation of two radicals, benzoyl and 2hydroxyl-2-propyl. ${ }^{48}$ The benzoyl radical reacts with the monomer by taking one $\pi$ electron from a terminal $\mathrm{C}=\mathrm{C}$ bond to form a $\mathrm{C}-\mathrm{C}$ bond with the monomer (Fig. $2 \mathrm{~b}$ ). The unpaired $\pi$ electron remains on the second $\mathrm{C}$ atom turning the whole monomer molecule into another radical. The reaction proceeds in the same way until a crosslinked polymer network is formed (Fig. 2c). 


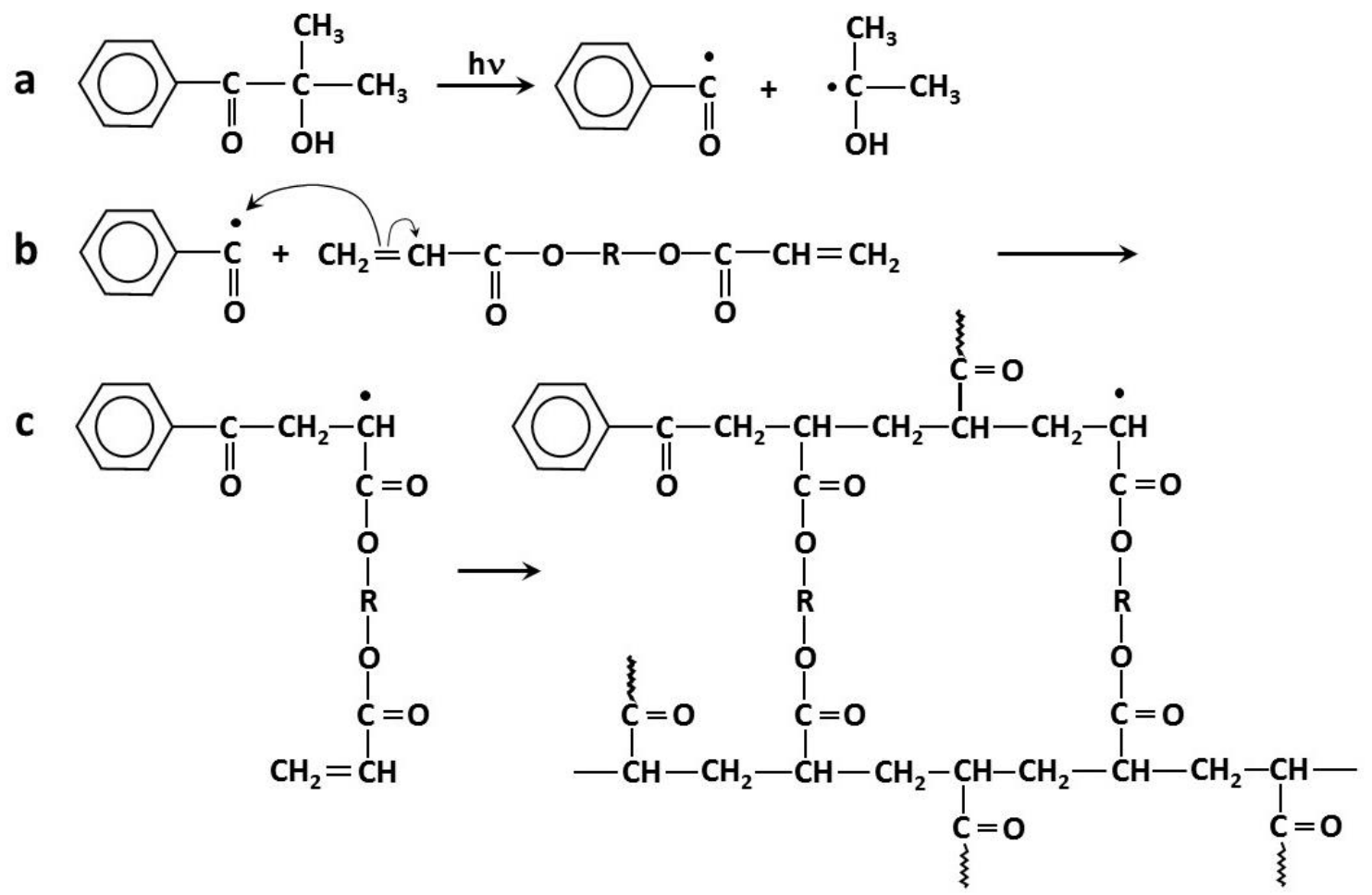

Figure 2. Photopolymerisation of HDDA monomer with 2-hydroxy-2-methylpropiophenone: (a) Photocleavage of the photoinitiator and formation of two free radicals; (b) Reaction between benzoyl radical and the monomer; (c) Formation of crosslinked polymer network. Adapted from Decker. $^{48}$

\section{Particles characterization}

\section{Attenuated total reflection-Fourier transform infrared (ATR-FTIR) spectroscopy. ATR-}

FTIR spectra in the range of $4000-400 \mathrm{~cm}^{-1}$ were recorded on a Thermo Scientific Nicolet iS50 ATR spectrometer with a monolithic diamond crystal. 2-3 mg of the sample was placed onto the Universal diamond ATR top-plate and the spectrum was acquired within $32 \mathrm{s.}$

Differential Scanning Calorimetry (DSC). Modulated DSC analysis was done using a TA Instruments model 2910 calorimeter. $10-15 \mathrm{mg}$ of the sample was placed in an aluminum pan and hermetically sealed. The sample pan was heated from 200 to $420^{\circ} \mathrm{C}$ at a rate of $1.5^{\circ} \mathrm{C} / \mathrm{min}$ and the difference in heat flow rate between the sample and empty pan was measured. The flow rate of purge gas (dry nitrogen) was maintained at $60 \mathrm{~mL} / \mathrm{min}$. 
Scanning Electron Microscopy (SEM). The morphology of the particles after curing was analyzed using a TM3030 benchtop SEM (Hitachi, Tabletop Microscope Europe) operating at an accelerating voltage of $15 \mathrm{keV}$. Prior to SEM, some of the particles were crashed between two glass slides to investigate their internal structure. The particles were coated with a 80:20 gold/palladium mixture prior to SEM to prevent accumulation of electrostatic charges on them. The sputtering rate was $0.85 \mathrm{~nm}$ per second at $2 \mathrm{kV}$ and $25 \mathrm{~mA}$ of plasma current.

X-ray Diffraction (XRD). Wide-angle XRD patterns were obtained using a Bruker D2 Phaser diffractometer fitted with a 1-dimensional LynxEYE ${ }^{\mathrm{TM}}$ detector. A copper X-ray source $(\mathrm{K} \alpha=$ $1.54184 \AA$ ) maintained at $30 \mathrm{kV}$ and $10 \mathrm{~mA}$ was used, with the $\mathrm{K} \beta$ radiation suppressed by a $0.5 \mathrm{~mm}$ thick nickel filter. Patterns were recorded over a $2 \theta$ range of $10-90^{\circ}$ with a step size of $0.02^{\circ}$ and an equivalent step time of $49.2 \mathrm{~s}$. Sample rotation was set at $15 \mathrm{rpm}$. Bruker's proprietary Eva 2.0 software was used to obtain the spectra.

Confocal Laser Scanning Microscopy (CLSM). The particle shells were stained with Nile Red, which was added to the oil phase prior to emulsification. The particles were analysed using a CLSM system (BIO-RAD Radiance2000 MP) mounted on a Nikon Eclipse TE300 microscope connected to a computer running Zeiss LaserSharp 2000 software. The sample was excited with a 1.5-mW helium-neon laser at $543 \mathrm{~nm}$. A $570 \mathrm{~nm}$ long-pass emission filter was used for image acquisition via confocal microscopy.

\section{Photocatalytic activity test}

$2 \mathrm{~g}$ of the microspheres loaded with $10 \mathrm{mg}$ of $\mathrm{TiO}_{2}$ were added to $80 \mathrm{~mL}$ of an aqueous $\mathrm{MB}$ solution placed in a $100-\mathrm{mL}$ beaker and stirred for $30 \mathrm{~min}$ in the dark prior to UV irradiation. The catalysis was carried out under a tubular Blacklight Blue lamp (20W T12 BLB ISL, Philips Ltd., Croydon) emitting at $365 \mathrm{~nm}$. The light irradiance was $0.9 \mathrm{~mW} / \mathrm{cm}^{2}$, measured by a UVX 
digital radiometer combined with a sensor cell (UVX-36 Ultra-Violet Products Ltd, Cambridge, UK). 1.5-mL aliquots of the irradiated solution were withdrawn with a Pasteur pipette every hour and the UV-vis absorption spectra of the samples were recorded using a Lambda $35 \mathrm{UV} / \mathrm{V}$ is spectrophotometer (PerkinElmer Ltd, Llantrisant). The dye concentration in the samples was determined from the calibration curve shown in the supporting information (Fig. S6).

\section{Results and Discussion}

\section{Production of single emulsions}

The formation of $\mathrm{TiO}_{2}$ laden monomer droplets is shown in Fig. 3a-d. Uniform droplets with $C V<2 \%$ were generated in dripping regime (Fig. 3a-c), for $L<3.3 D_{d},{ }^{49}$ where $L$ is the jet length at the breakup point and $D_{d}$ is the droplet diameter. At low outer phase flow rate, $Q_{2}$ (Fig. 3a), the dispersed phase jet occupies almost the entire cross section of the orifice and the outer phase flows through a narrow annular gap between the orifice wall and the oil-water interface. When $Q_{2}$ increased from 0.6 to $1 \mathrm{~mL} / \mathrm{h}, D_{d}$ was reduced from 154 to $127 \mu \mathrm{m}$ (Fig. 3a-b). $D_{d}$ was reduced by decreasing $Q_{1}$ at constant $Q_{2}$ (Fig. 3b-c), due to shorter necking time $t_{n}$. The final droplet volume $V_{d}$ is given by: ${ }^{50} V_{d}=V_{c}+t_{n} Q_{1}$. First, a droplet grows to the critical volume $V_{c}$, defined by the balance between the shear force and the interfacial tension. After that, the droplet continues to grow for time $t_{n}$, due to additional inflow of the dispersed phase through the neck, until eventually the droplet pinches off from the jet. For low $Q_{1}$, the droplet growth is dominated by the first stage $\left(V_{d} \approx V_{c}\right)$ and $V_{d}$ is independent of $Q_{1}$.

The presence of $\mathrm{TiO}_{2}$ in the oil phase did not compromise the drop size uniformity even at low $Q_{2} / Q_{1}$ values (Fig. $\mathrm{S} 1$ in the supporting information), because $\mathrm{TiO}_{2}$ nanoparticles were well dispersed in the oil phase due to stabilizing effect of PGPR. At high continuous phase flow rates 
(Fig. 3d), the dispersed phase was pulled into a long jet, resulting in large and non-uniform drops $(C V>7 \%)$. After collection on a microscope slide, the droplets generated in dripping regime self-organized into regular 2D hexagonal lattice (Fig. 3e). The droplet lattice was highly ordered, reflecting high size uniformity of the droplets formed in dripping regime.

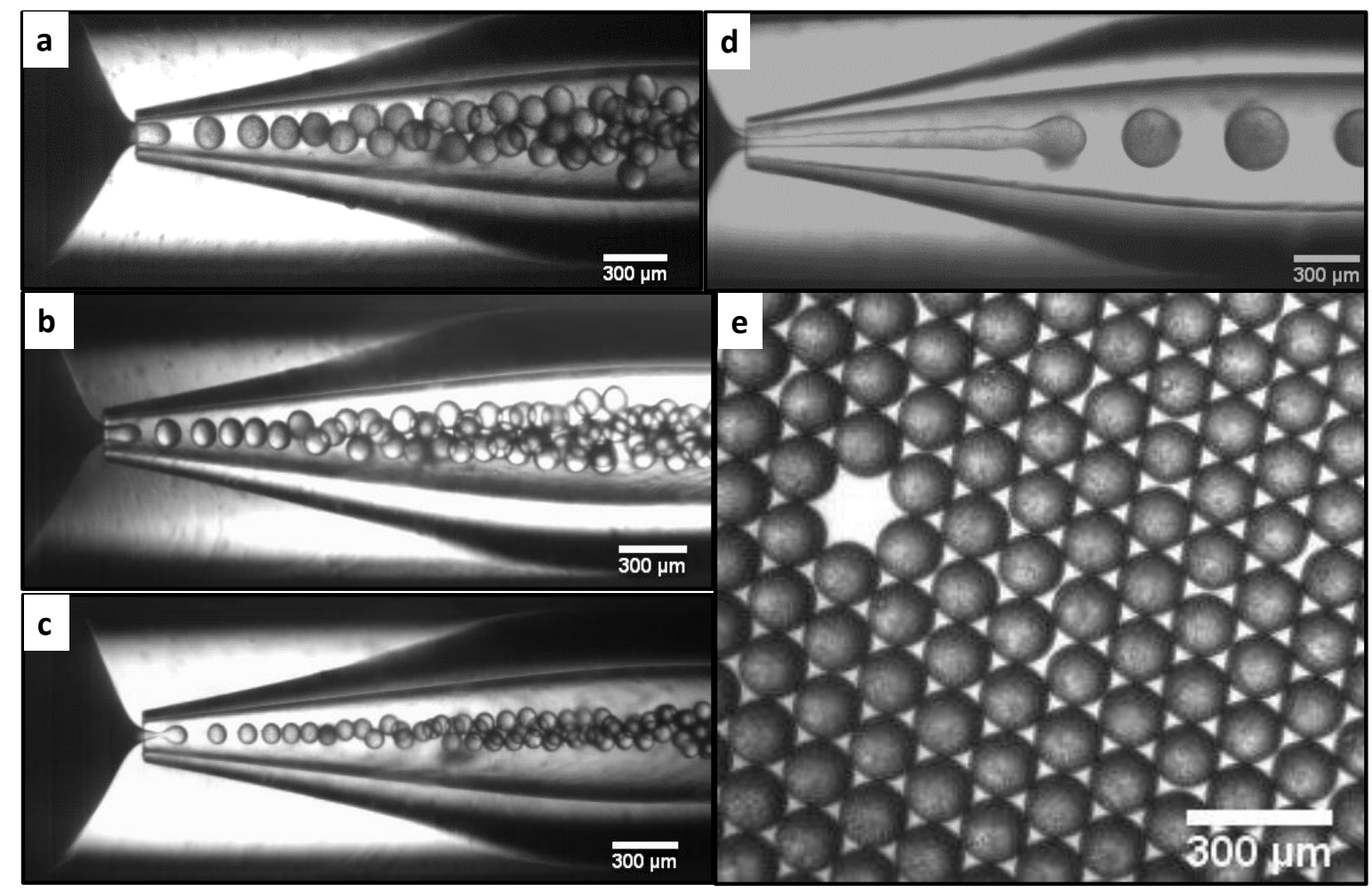

Figure 3. Formation of $(\mathrm{S} / \mathrm{O}) / \mathrm{W}$ emulsions at $D_{\text {orif }}=150 \mu \mathrm{m}:$ (a) $Q_{1}=0.15 \mathrm{~mL} / \mathrm{h}, Q_{2}=0.6$ $\mathrm{mL} / \mathrm{h}, C V=1.6 \%, D_{d}=154 \mu \mathrm{m}, f=78 \mathrm{~Hz}$; (b) $Q_{1}=0.35 \mathrm{~mL} / \mathrm{h}, Q_{2}=1 \mathrm{~mL} / \mathrm{h}, C V=0.76 \%$, $D_{d}=127 \mu \mathrm{m}, f=105 \mathrm{~Hz}$; (c) $Q_{1}=0.15 \mathrm{~mL} / \mathrm{h}, Q_{2}=1 \mathrm{~mL} / \mathrm{h}, C V=1.4 \%, D_{d}=100 \mu \mathrm{m}, f=125$ $\mathrm{Hz}$; (d) $Q_{1}=0.15 \mathrm{~mL} / \mathrm{h}, Q_{2}=5 \mathrm{~mL} / \mathrm{h}, C V=7.5 \%, D_{d}=236 \mu \mathrm{m}, f=26 \mathrm{~Hz}$; (e) Droplets generated in Fig. 3 a self-assembled on a micoscope slide. $Q_{1}-$ Dispersed phase flow rate, $Q_{2}-$ Continuous phase flow rate, $f$ - Droplet generation frequency, $D_{d}$ - Droplet diameter, $D_{\text {orif }}-$ orifice diameter.

Fig. 4a shows $D_{d}$ in dripping regime as a function of $Q_{2}$ at constant $Q_{1}$. Clearly, $D_{d}$ decreased on increasing $Q_{2}$, due to higher drag force acting on the dispersed phase. On the other hand, the drop generation frequency, $f$ increased with $Q_{2}$, because $f$ is inversely proportional to $D_{d}^{3} . D_{d}$ 
increased on increasing $Q_{1}$ at constant $Q_{2}$ (Fig. 4b), which agrees with the equation: $V_{d}=V_{c}+$ $t_{n} Q_{1}$. The $D_{d}$ values predicted from the equation: $D_{d}=\left[6 Q_{1} /(f \pi)\right]^{1 / 3}$ are plotted as solid red lines and they are very close to the experimental $D_{d}$ values. The droplet size and drop generation frequency showed negligible variations with time over 5 hours (Fig. S2).

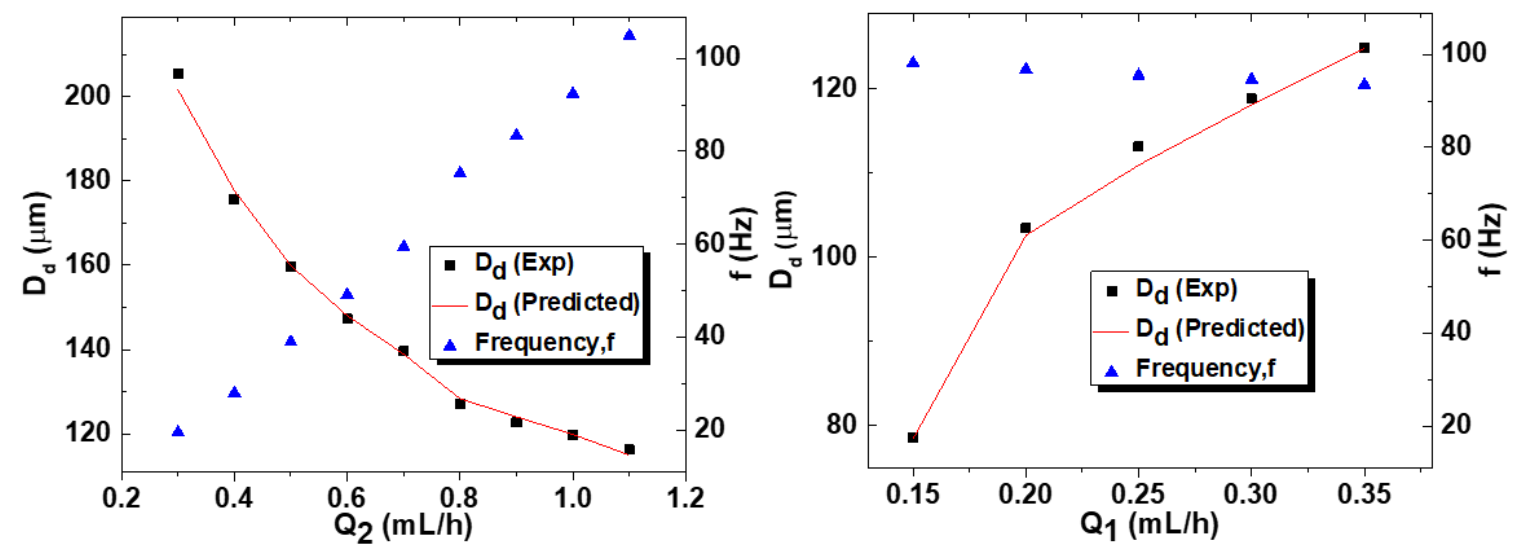

Figure 4. The variation of droplet size, $D_{d}$ and generation frequency, $f$ of $(\mathrm{S} / \mathrm{O}) / \mathrm{W}$ emulsion formed in dripping regime at $D_{\text {orif }}=150 \mu \mathrm{m}$ : (a) The effect of outer phase flow rate, $Q_{2}$ at $Q_{1}=0.15 \mathrm{~mL} / \mathrm{h}$; (b) The effect of inner phase flow rate, $Q_{1}$ at $Q_{2}=1 \mathrm{~mL} / \mathrm{h}$.

In Fig. 5a, $D_{d} / D_{\text {orif }}$ is plotted against $Q_{2} / Q_{1}$ on a log-log scale. A good linear relationship with $R=-0.99$ was obtained in dripping regime, with the best-fit line equation:

$$
\frac{D_{d}}{D_{\text {orif }}}=1.3\left(\frac{Q_{2}}{Q_{1}}\right)^{-0.42}
$$

The exponent of -0.42 is close to the range $[-0.40,-0.37]$ reported previously for different microfluidic geometries..$^{51-53}$

In Fig. $5 \mathrm{~b}, D_{d} / D_{\text {orif }}$ was plotted against $\left(Q_{1} / Q_{t}\right)^{1 / 2}$, where $Q_{t}=Q_{1}+Q_{2}$. The dripping to jetting transition occurred at $\left(Q_{1} / Q_{t}\right)^{1 / 2}=0.4$, i.e. at $Q_{1} / Q_{t}=0.16$. The dripping regime was stable at $\left(Q_{1} / Q_{t}\right)^{1 / 2}>0.4$. A deviation from the straight line of the data point at $\left(Q_{1} / Q_{t}\right)^{1 / 2}=$ 0.7 might be due to squeezing regime prevailing under such conditions. The proportionality 
between $D_{d} / D_{\text {orif }}$ and $\sqrt{Q_{1} / Q_{t}}$ found in Fig. $5 \mathrm{~b}$ follows from the analytical model developed by Utada et al. ${ }^{38}$ In dripping regime, both fluids flow through the orifice at approximately the same velocity, $U_{1}=U_{2}$, which is confirmed by CFD modelling. ${ }^{49,54}$ Thus, the ratio of volumetric flow rates is equal to the ratio of corresponding cross-sectional areas of fluid streams:

$$
\frac{Q_{1}}{Q_{2}}=\frac{\pi D_{\text {jet }}^{2} / 4}{\left(\pi D_{\text {orif }}^{2} / 4-\pi D_{\text {jet }}^{2} / 4\right)}
$$

The wavelength $\lambda$ of the fastest growing mode of the Rayleigh-Plateau instability is $\lambda=$ $k\left(D_{j e t} / 2\right)$, where $k$ is a constant which depends on the viscosity ratio of fluids, $\alpha=\mu_{1} / \mu_{2}{ }^{55}$ The final droplet volume, $V_{d}$ is approximately equal to the volume of a fluid cylinder of length $\lambda$ :

$$
V_{d}=\frac{\pi D_{d}^{3}}{6}=\frac{\pi \lambda D_{j e t}^{2}}{4}=\frac{1}{8} k \pi D_{j e t}^{3}
$$

By combining Equations (2) and (3):

$$
\frac{D_{d}}{D_{\text {orif }}}=\left(\frac{3}{4} k\right)^{\frac{1}{3}}\left(\frac{Q_{1}}{Q_{1}+Q_{2}}\right)^{\frac{1}{2}}=\left(\frac{3}{4} k\right)^{\frac{1}{3}} \sqrt{\frac{Q_{1}}{Q_{\mathrm{t}}}}
$$

In Fig. 5 (b), Eq. (4) nicely overlaps with the experimental data yielding the proportionality constant $(3 k / 4)^{1 / 3}$ of 1.73 , from which $k=6.9$. This $k$ value is reasonably close to the theoretical $k$ value of 7.75 predicted by Tomotika ${ }^{55}$ at $\alpha=0.3$.
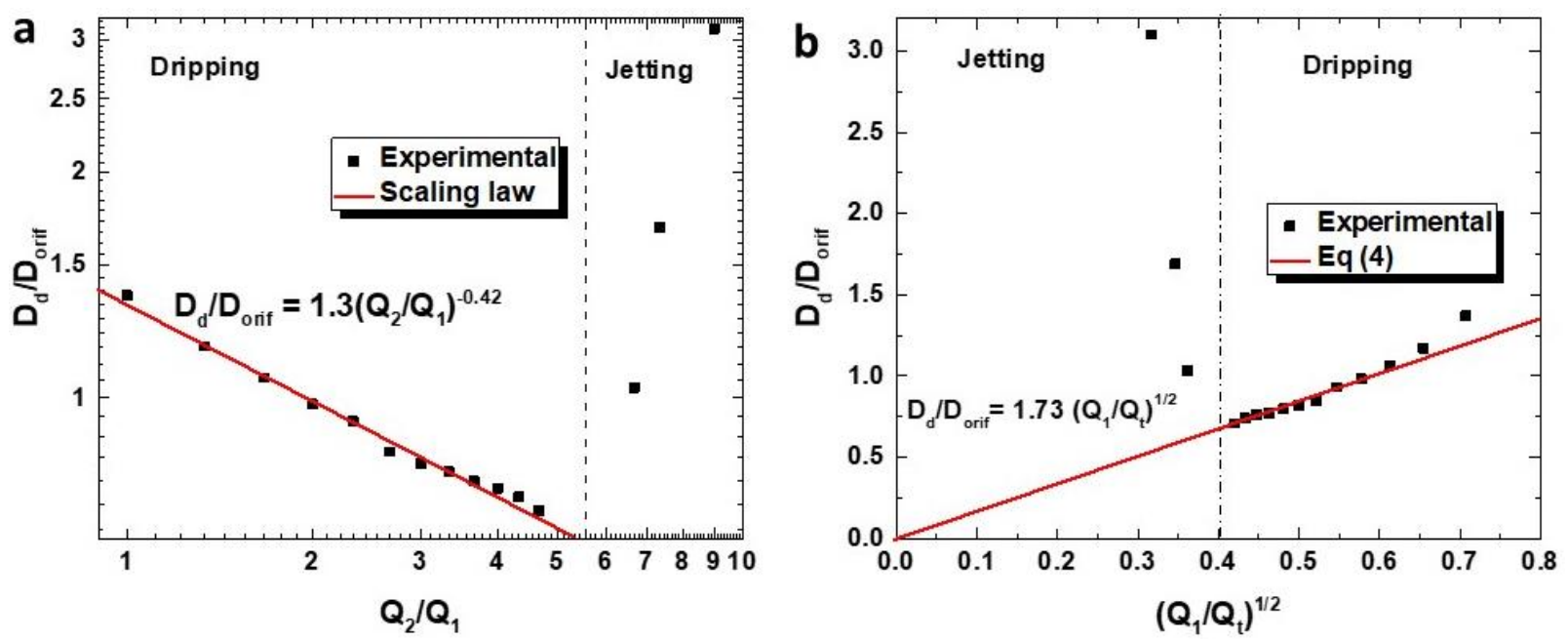
Figure 5. (a) A relationship between $D_{d} / D_{\text {orif }}$ and the flow rate ratio, $Q_{2} / Q_{1}$ in a log-log scale. The equation of the straight line is $D_{d} / D_{\text {orif }}=A\left(Q_{2} / Q_{1}\right)^{B}$, where $A=1.3 \pm 0.014, B=$ $-(0.42 \pm 0.03)$, and the correlation coefficient is $R=-0.99$; (b) The droplet diameters $D_{d}$ scaled by the orifice diameter, $D_{\text {orif }}$ as a function of $\left(Q_{1} / Q_{t}\right)^{1 / 2}$.

\section{Production of multiple emulsions}

In Fig. 6a, the sizes of inner and outer drops produced in dripping regime were plotted against $Q_{1}$ at constant flow rates of the middle and outer fluids, $Q_{2}$ and $Q_{3}$. The shell thickness, $\delta$ ranged between 70 and $40 \mu \mathrm{m}$ by varying $Q_{1}$, which is a facile way to control the mechanical properties and permeability of the capsules. Higher $Q_{1}$ values resulted in larger inner droplets due to higher inflow of inner fluid into a growing drop during jet pinch-off. ${ }^{56}$ The droplet generation rate increased with increasing $Q_{1}$, which led to smaller outer drops with thinner shells (Fig. 6 b-c). The $C V$ of both inner and outer drops was less than $2 \%$ in all cases. The internal morphology of single core and dual core droplets was confirmed using confocal microscopy (Fig. 6 d, f).
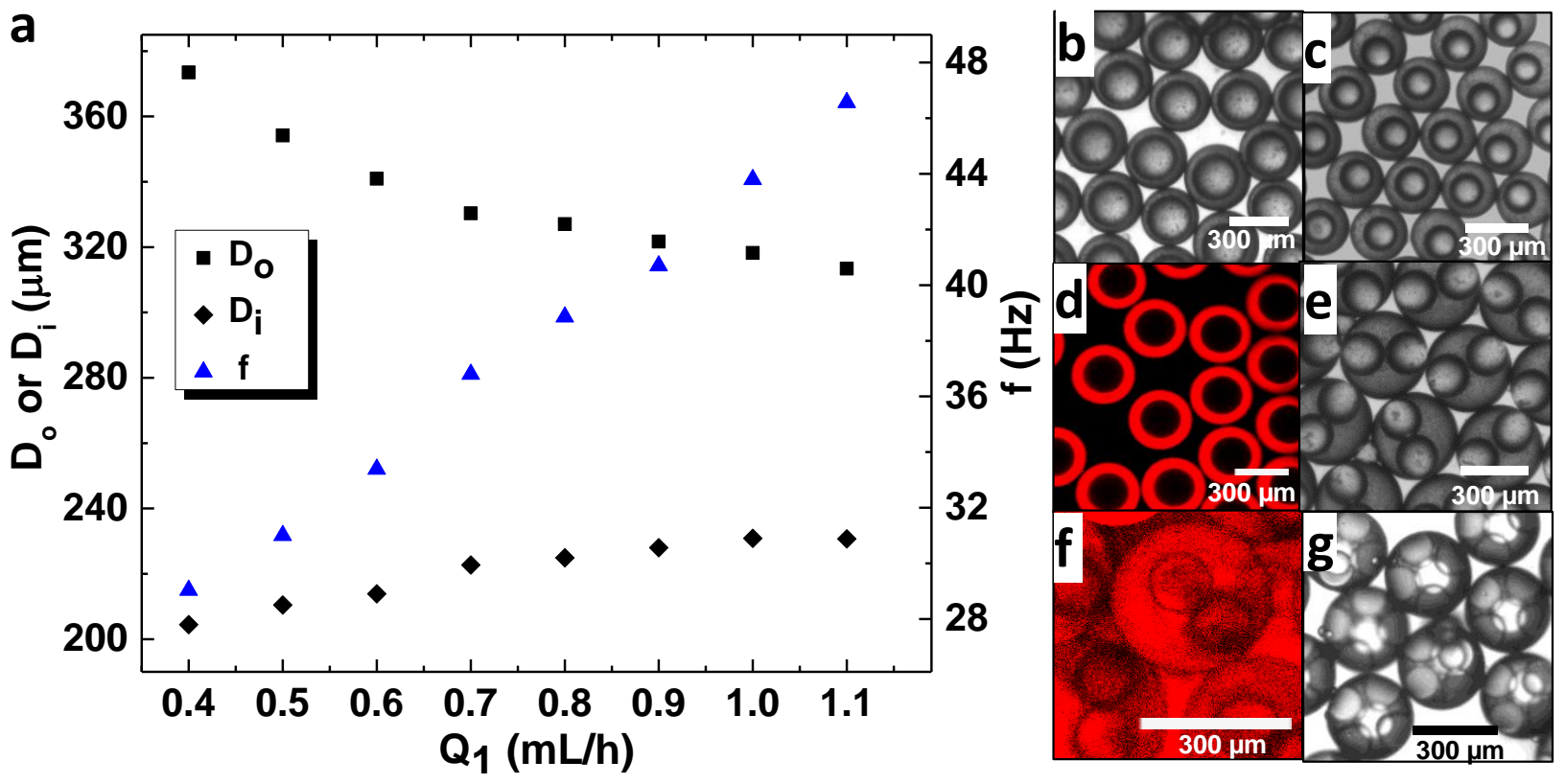
Figure 6. (a) The size of inner and outer drops, $D_{i}$ and $D_{o}$ and generation frequency, $f$ for double emulsions formed in dripping regime at $D_{N}=50 \mu \mathrm{m}, D_{\text {orif }}=150 \mu \mathrm{m}, Q_{2}=2 \mathrm{~mL} / \mathrm{h}$, and $Q_{3}=4.8$ $\mathrm{mL} / \mathrm{h}$; (b-e) Micrographs of generated droplets: (b) $Q_{1}=0.5 \mathrm{~mL} / \mathrm{h}, Q_{2}=2 \mathrm{~mL} / \mathrm{h}, Q_{3}=4.8 \mathrm{~mL} / \mathrm{h}$, $D_{o}=348 \mu \mathrm{m}, D_{i}=207 \mu \mathrm{m}, C V_{i}=0.5 \%, C V_{o}=0.23 \%, \delta=71 \mu \mathrm{m} ;(\mathrm{c}) Q_{1}=1.2 \mathrm{~mL} / \mathrm{h}, Q_{2}=2$ $\mathrm{mL} / \mathrm{h}, Q_{3}=4.8 \mathrm{~mL} / \mathrm{h}, D_{o}=320 \mu \mathrm{m}, D_{i}=235 \mu \mathrm{m}, C V_{i}=1.4 \% C V_{o}=1.2 \%, \delta=42 \mu \mathrm{m}$; (d) $Q_{1}=$ $0.9 \mathrm{~mL} / \mathrm{h}, Q_{2}=2 \mathrm{~mL} / \mathrm{h}, Q_{3}=4.8 \mathrm{~mL} / \mathrm{h}, D_{o}=321 \mu \mathrm{m}, D_{i}=234 \mu \mathrm{m}, C V_{i}=0.5 \% C V_{o}=0.23 \%, \delta=$ $43 \mu \mathrm{m}$; (e-f) $Q_{1}=1.2 \mathrm{~mL} / \mathrm{h}, Q_{2}=2.2 \mathrm{~mL} / \mathrm{h}, Q_{3}=4.2 \mathrm{~mL} / \mathrm{h}, D_{o}=420 \mu \mathrm{m}, D_{i}=213 \mu \mathrm{m}, C V_{o}=$ $1.9 \%, C V_{i}=2 \% ;(\mathrm{g}) Q_{1}=0.32 \mathrm{~mL} / \mathrm{h}, Q_{2}=2.5 \mathrm{~mL} / \mathrm{h}, Q_{3}=3.5 \mathrm{~mL} / \mathrm{h}, D_{o}=621 \mu \mathrm{m}, C V_{o}=0.6 \%$.

One way of increasing the number of inner drops is to increase $Q_{2}$ along with a decrease in $Q_{3}$ at constant $Q_{1}$. Indeed, as $Q_{2}$ was increased from 2 to 2.2 to $2.5 \mathrm{~mL} / \mathrm{h}$ and $Q_{3}$ decreased from 4.8 to 4.2 to $3.5 \mathrm{~mL} / \mathrm{h}$, the number of inner drops increased from 1 to 2 to 5 (Fig. $6 \mathrm{c}, \mathrm{e}, \mathrm{g}$ ). The same behavior can be predicted from the phase diagrams developed by Nabavi et al. ${ }^{57}$

The formation of multiple emulsions with tunable drop size, shell thickness and number of inner drops is shown in Fig. 7. Increasing $Q_{1}$ from 0.4 to $1 \mathrm{~mL} / \mathrm{h}$ suppressed jetting of the middle phase and resulted in a thinner shell (Figs. $7 \mathrm{a}-\mathrm{b}$ ). Further increase in $Q_{1}$ to $1.2 \mathrm{~mL} / \mathrm{h}$ led to encapsulation of two inner drops in each outer drop $\left(f_{2} / f_{1} \approx 2\right)$, Fig. 7c. The number of inner drops, $n_{1}$ and their volume fraction $\phi_{1}$ in a compound drop consistently increased on decreasing $Q_{2} / Q_{1}:$ at $Q_{2} / Q_{1}=11.9, n_{i}=3$ and $\phi_{1}=7.8 \%$ (Fig. $7 \mathrm{~d}$ ); at $Q_{2} / Q_{1}=9.6, n_{i}=4$ and $\phi_{1}=9.4 \%$ (Fig. 7e); at $Q_{2} / Q_{1}=7.8, n_{i}=5$ and $\phi_{1}=11.4 \%$ (Fig. 7f); and at $Q_{2} / Q_{1}=6.2, n_{i}=6$ and $\phi_{1}=13.9 \%$ (Fig. 7g). Finally, at $Q_{2} / Q_{1}=2.3$ (Fig. 7h), the middle phase jet could not be broken up, resulting in a continuous jet of middle phase loaded with numerous inner droplets. After UV curing, this jet can be transformed into a multi-core polymer microfiber embedded with $\mathrm{TiO}_{2}$. 


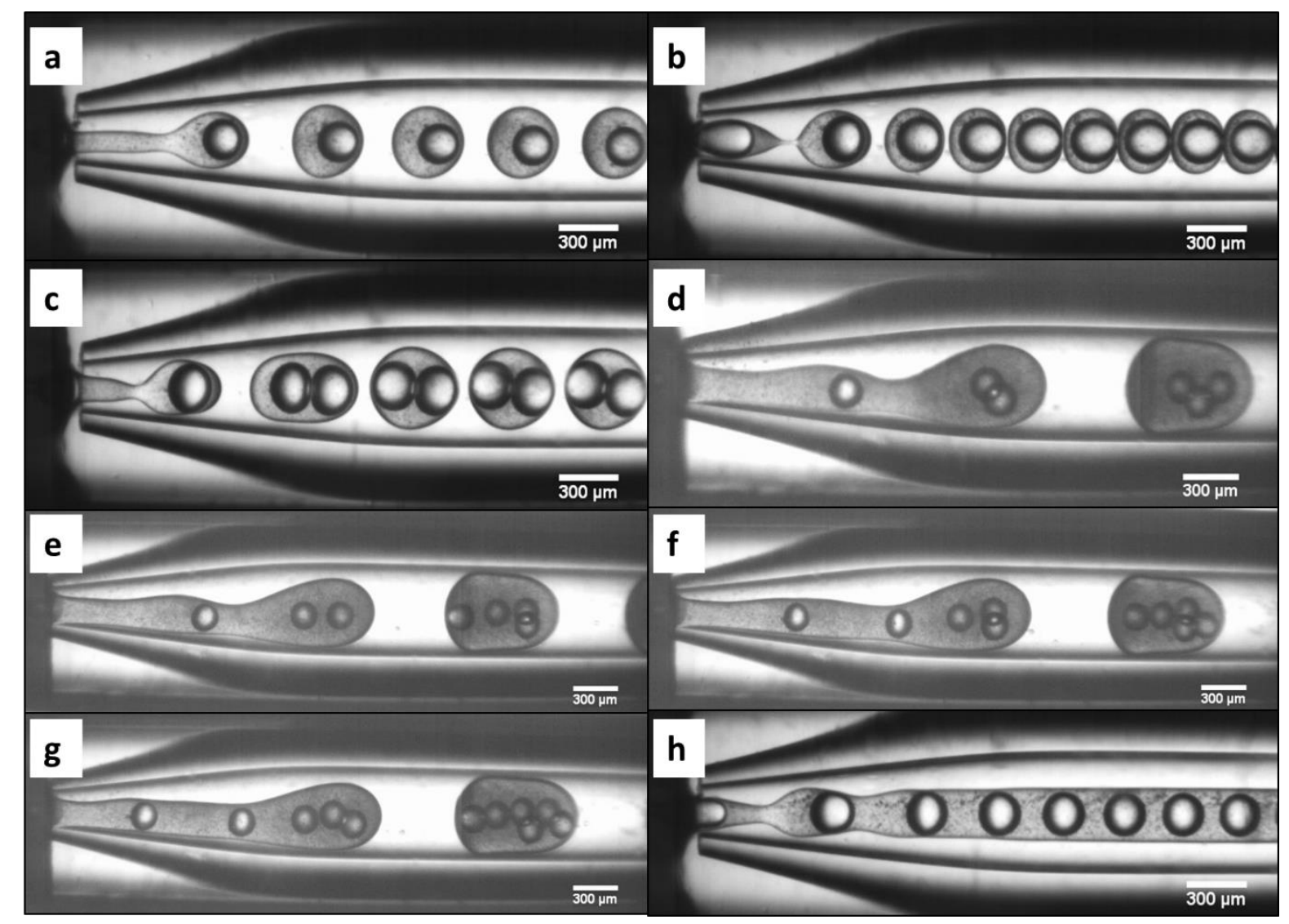

Figure 7. Generation of $\mathrm{W}_{1} /(\mathrm{S} / \mathrm{O}) / \mathrm{W}_{2}$ emulsions at different fluid flow rates: (a) $Q_{1}=0.4 \mathrm{~mL} / \mathrm{h}$, $Q_{2}=2 \mathrm{~mL} / \mathrm{h}, Q_{3}=4.8 \mathrm{~mL} / \mathrm{h}, D_{o}=373 \mu \mathrm{m}, D_{i}=211 \mu \mathrm{m}, \delta=81 \mu \mathrm{m}, f=24 \mathrm{~Hz}$; (b) $Q_{1}=1 \mathrm{~mL} / \mathrm{h}, Q_{2}=2$ $\mathrm{mL} / \mathrm{h}, Q_{3}=4.8 \mathrm{~mL} / \mathrm{h}, f=43 \mathrm{~Hz}, D_{o}=321 \mu \mathrm{m}, D_{i}=238 \mu \mathrm{m}, \delta=41.5 \mu \mathrm{m}, C V_{o}=1.7 \%, C V_{i}=2 \%$; (c) $Q_{1}=1.2 \mathrm{~mL} / \mathrm{h}, Q_{2}=2.2 \mathrm{~mL} / \mathrm{h}, Q_{3}=4.3 \mathrm{~mL} / \mathrm{h}, D_{o}=429 \mu \mathrm{m}, D_{i}=(242,238) \mu \mathrm{m}, f_{o}=20.2 \mathrm{~Hz}, f_{i}=41$ $\mathrm{Hz}, C V_{o}=0.4, C V_{i}=(0.6,1.7) \%$; (d) $Q_{1}=0.21 \mathrm{~mL} / \mathrm{h}, Q_{2}=2.5 \mathrm{~mL} / \mathrm{h}, Q_{3}=3.5 \mathrm{~mL} / \mathrm{h}$; (e) $Q_{1}=0.26$ $\mathrm{mL} / \mathrm{h}, Q_{2}=2.5 \mathrm{~mL} / \mathrm{h}, Q_{3}=3.5 \mathrm{~mL} / \mathrm{h}$; (f) $Q_{1}=0.32 \mathrm{~mL} / \mathrm{h}, Q_{2}=2.5 \mathrm{~mL} / \mathrm{h}, Q_{3}=3.5 \mathrm{~mL} / \mathrm{h} ;$ (g) $Q_{1}=0.4$ $\mathrm{mL} / \mathrm{h}, Q_{2}=2.5 \mathrm{~mL} / \mathrm{h}, Q_{3}=3.5 \mathrm{~mL} / \mathrm{h}$; (h) $Q_{1}=1.2 \mathrm{~mL} / \mathrm{h}, Q_{2}=2.8 \mathrm{~mL} / \mathrm{h}, Q_{3}=4.8 \mathrm{~mL} / \mathrm{h}$.

\section{Production of particles with encapsulated active ingredients}

Phase change materials (PCMs) such as higher hydrocarbons can be encapsulated inside microcapsules to achieve simultaneous thermal energy storage and UV shielding. ${ }^{47}$ The energy storage capacity of these bifunctional capsules can be tuned in a facile way by changing the size and number of inner cavities. The capsules can also be loaded with a UV-sensitive material, ${ }^{58}$ whose release can be triggered by friction or pressure, like in scratch-and-sniff stickers. The 
inclusion of $\mathrm{TiO}_{2}$ in the polymer shell prevents the premature release of encapsulated material and their light-induced damage and improves mechanical stability of the capsules.
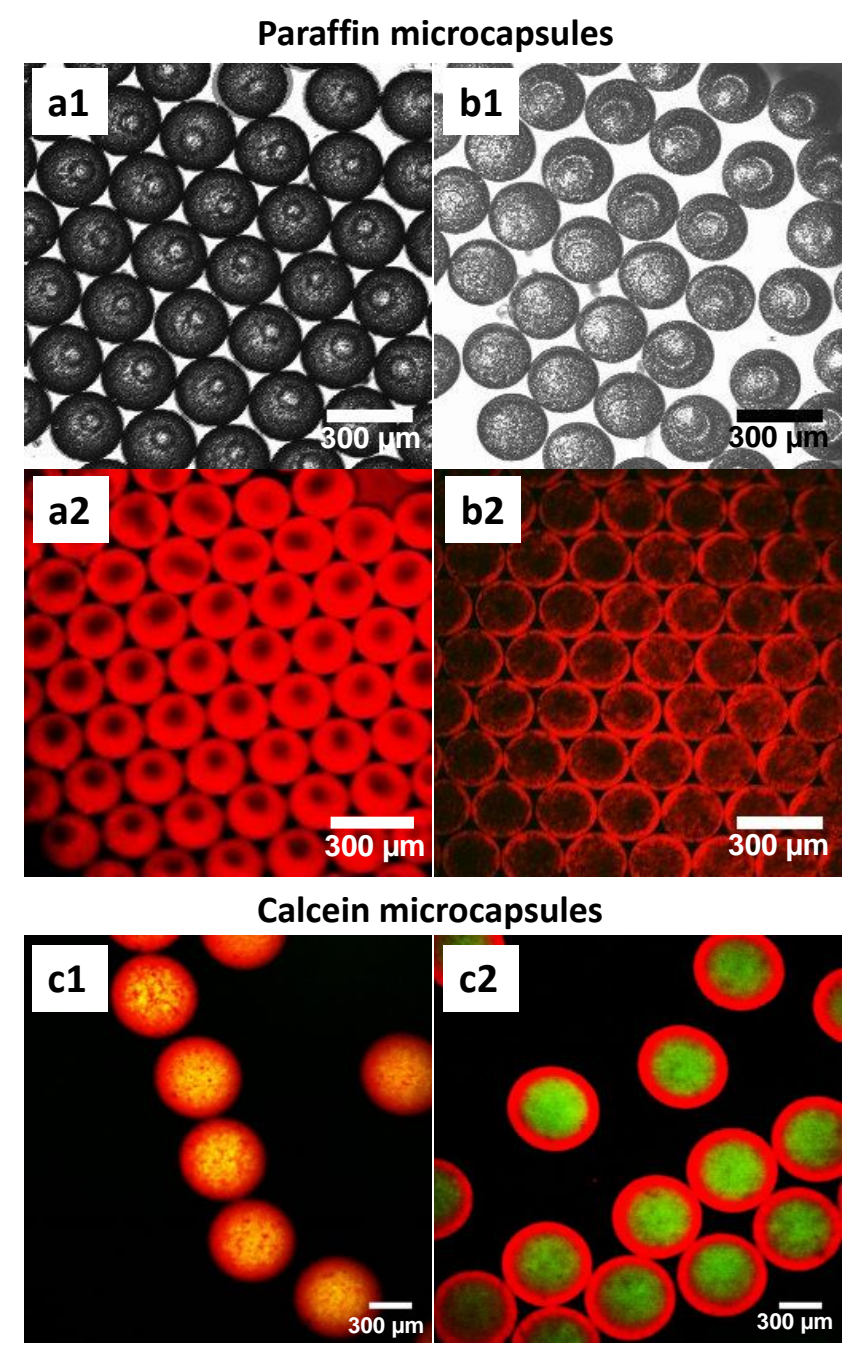

Figure 8. Core/shell microcapsules whose cores are loaded with different encapsulants: $(a, b)$ Microscopic and confocal images of microcapsules loaded with liquid paraffin, (a) with smaller core, (b) with larger core. Inner fluid: liquid paraffin, Middle fluid: $0.5 \mathrm{wt} \% \mathrm{TiO}_{2}, 3 \mathrm{wt} \%$ PGPR, and $1 \mathrm{wt} \%$ Darocur 1173 in HDDA, Outer fluid: $3 \mathrm{wt} \%$ PVA and $40 \mathrm{wt} \%$ glycerol in DI water; (c) Microcapsules loaded with aqueous calcein solution. Inner fluid: $1.25 \mathrm{ppm}$ calcein in water, Middle fluid: $0.5 \mathrm{wt} \% \mathrm{TiO}_{2}, 3 \mathrm{wt} \%$ PGPR, and $1 \mathrm{wt} \%$ Darocur 1173 in HDDA, Outer phase: 3 $\mathrm{wt} \%$ PVA, $40 \mathrm{wt} \%$ glycerol in DI water, c1 particles after UV curing, c2 droplets.

Polymer microcapsules with encapsulated liquid paraffin and aqueous calcein solution were produced using $\mathrm{O}_{1} /\left(\mathrm{S} / \mathrm{O}_{2}\right) / \mathrm{W}$ and $\mathrm{W}_{1} /(\mathrm{S} / \mathrm{O}) / \mathrm{W}_{2}$ emulsions as templates (Fig. 8). Paraffin belongs 
to PCMs which are known to be excellent for thermal energy storage. ${ }^{59}$ The encapsulation of paraffin was confirmed by DSC (Fig. S3). Capsules with different sizes of paraffin core were produced (Fig. 8a-b) allowing the adjustment of energy storage capacity. Various hydrocarbons with different melting points and latent heats can be encapsulated to tune the thermal properties of the caspules. $\mathrm{TiO}_{2}$ incorporated within the polymer shell can repel the sun's UV rays and therefore, these capsules can be used in smart clothing for simultaneous UV shielding and thermal storage. The encapsulation of aqueous calcein solutions was demonstrated in Fig. 8c1-2. The encapsulation efficiency was $100 \%$, as no traces of the fluorescent dye were observed in the outer aqueous phase either before UV curing (Fig. 8c2) or after polymerisation (Fig. 8c1).

\section{Characterisation of the synthesized composite polymer particles}

SEM. The SEM image of $\mathrm{TiO}_{2}$-filled polymer microspheres is shown in Fig. 9a. Capsules with a single cavity were formed by polymerisation of core-shell drops. To confirm the presence of internal cavity and the shell integrity after polymerisation, the particles were crashed between two microscope slides prior to SEM imaging (Fig. 9b), or the shell was punched (Fig. 9c). Small shallow pores on the particle surface in Fig. 9 (c) were probably caused by the extraction of unreacted monomer from the shell, while white scattered dots are $\mathrm{TiO}_{2}$ nanoparticles embedded in the polymer matrix. An eccentric position of the internal cavity in Fig. $9 \mathrm{~b}$ with a shell thickness varying around the circumference from $33 \mu \mathrm{m}$ to $63 \mu \mathrm{m}$ was the result of the density mismatch between inner and middle phase. The droplets shrink during polymerisation since the average distance between the monomer molecules is larger than that between the repeating units in the crosslinked polymer. The shrinkage may lead to internal stress in the material, triggering the formation of a hole in the shell. ${ }^{60}$ The hole formation was avoided here by optimising the 
intensity of UV light and exposure time. The polymerisation of monomer drops with multiple inner droplets resulted in multiple inner compartments, as shown in Fig. 9d.

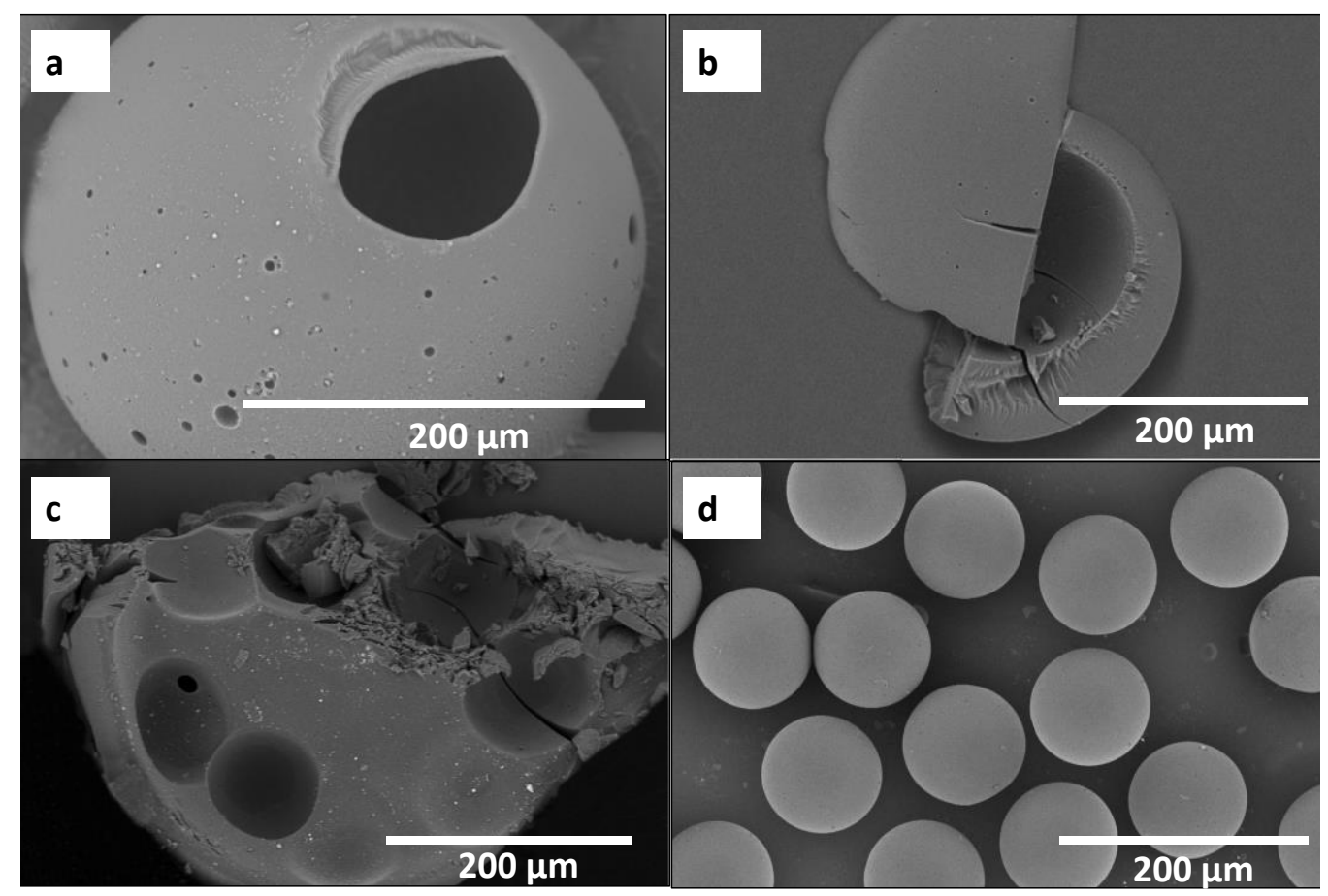

Figure 9. SEM images of particles after UV curing: (a) Solid microspheres; (b) Mechanically crushed core-shell capsule; (c) Core-shell capsule with a single hole punched in the shell; (d) Mechanically crushed multi-core capsules.

FTIR. The polymerisation of HDDA can be monitored using FTIR by following the stretching and twisting of the carbon-carbon double bond, which appears at the frequencies of 1600$1660 \mathrm{~cm}^{-1}$ and $1400-1430 \mathrm{~cm}^{-1}$, respectively. ${ }^{61}$ In Fig. 10a, the FTIR spectrum of HDDA showed absorption bands at $1635 \mathrm{~cm}^{-1}$ (peak 3) and $1407 \mathrm{~cm}^{-1}$ (peak 4), due to the stretching and twisting of the $\mathrm{C}=\mathrm{C}$ bond in the monomer, respectively. Both bands were weaker in the polymer due to conversion of $\mathrm{C}=\mathrm{C}$ bonds into $\mathrm{C}-\mathrm{C}$ bonds. Strong bands of HDDA at $\sim 1720 \mathrm{~cm}^{-1}$ (peak 2) and $\sim 1180 \mathrm{~cm}^{-1}$ (peak 5), which can be attributed to the stretching vibrations of the $\mathrm{C}=\mathrm{O}$ and $\mathrm{C}-\mathrm{O}$ bonds, respectively, were unchanged in the polymer, since these bonds were not affected by 
polymerisation. Two bands at $2939 \mathrm{~cm}^{-1}$ and $2861 \mathrm{~cm}^{-1}$ (peak 1) corresponding to the $=\mathrm{C}-\mathrm{H}$ stretching vibrations increased after polymerisation due to formation of new single bonds. The band at $982 \mathrm{~cm}^{-1}$ (peak 6), which can be assigned to the out-of-plane bending of $=\mathrm{C}-\mathrm{H}$ in vinyl groups, was weaker in poly(HDDA), providing another evidence for the conversion of $\mathrm{C}=\mathrm{C}$ bonds during polymerisation. The FTIR spectra of poly(HDDA) were not significantly affected by the embedded $\mathrm{TiO}_{2}$ particles, due to low percentage of $\mathrm{TiO}_{2}$ in the polymer matrix. The same behavior was found in polystyrene/ $\mathrm{TiO}_{2}$ composite films containing about $1 \%$ of $\mathrm{TiO}_{2}{ }^{62}$

XRD. The XRD patterns of pure $\mathrm{TiO}_{2}, \mathrm{TiO}_{2}$ embedded in poly(HDDA), pure poly(HDDA), and physical mixture of $\mathrm{TiO}_{2}$ and poly(HDDA) are shown in Fig. $9 \mathrm{~b}$. A broad peak at $20^{\circ}$ was observed for pure poly(HDDA), confirming its amorphous structure. ${ }^{63}$ The XRD pattern of pure $\mathrm{TiO}_{2}$ shows high-intensity narrow peaks typical for crystalline materials. The peaks reveal the presence of both anatase and rutile phases, as Degussa $\mathrm{P} 25 \mathrm{TiO}_{2}$ has a bicrystalline structure. The peaks at $25.26^{\circ}, 37.78^{\circ}, 48.00^{\circ}, 53.79^{\circ}, 55.02^{\circ}, 62.63^{\circ}, 68.79^{\circ}, 70.38^{\circ}$, and $75.10^{\circ}$ are related to the anatase phase and the peaks at $27.39^{\circ}, 36.02^{\circ}, 41.22^{\circ}, 56.61^{\circ}$, and $64.01^{\circ}$ correspond to the rutile phase of $\mathrm{TiO}_{2}{ }^{64}$ The XRD patterns of $\mathrm{TiO}_{2}$-embedded poly(HDDA) and a mechanical mixture of $\mathrm{TiO}_{2}$ and PHDDA show a broad peak at $20^{\circ}$ corresponding to poly(HDDA), but also some of the $\mathrm{TiO}_{2}$ peaks. $\mathrm{The}^{\mathrm{TiO}} 2$ peaks are much more intense in the physical mixture of $\mathrm{TiO}_{2}$ and poly(HDDA) than in the sample containing $\mathrm{TiO}_{2}$ embedded in the polymer matrix, indicating that $\mathrm{TiO}_{2}$ nanoparticles were well dispersed in the polymer network. 
(a) FTIR

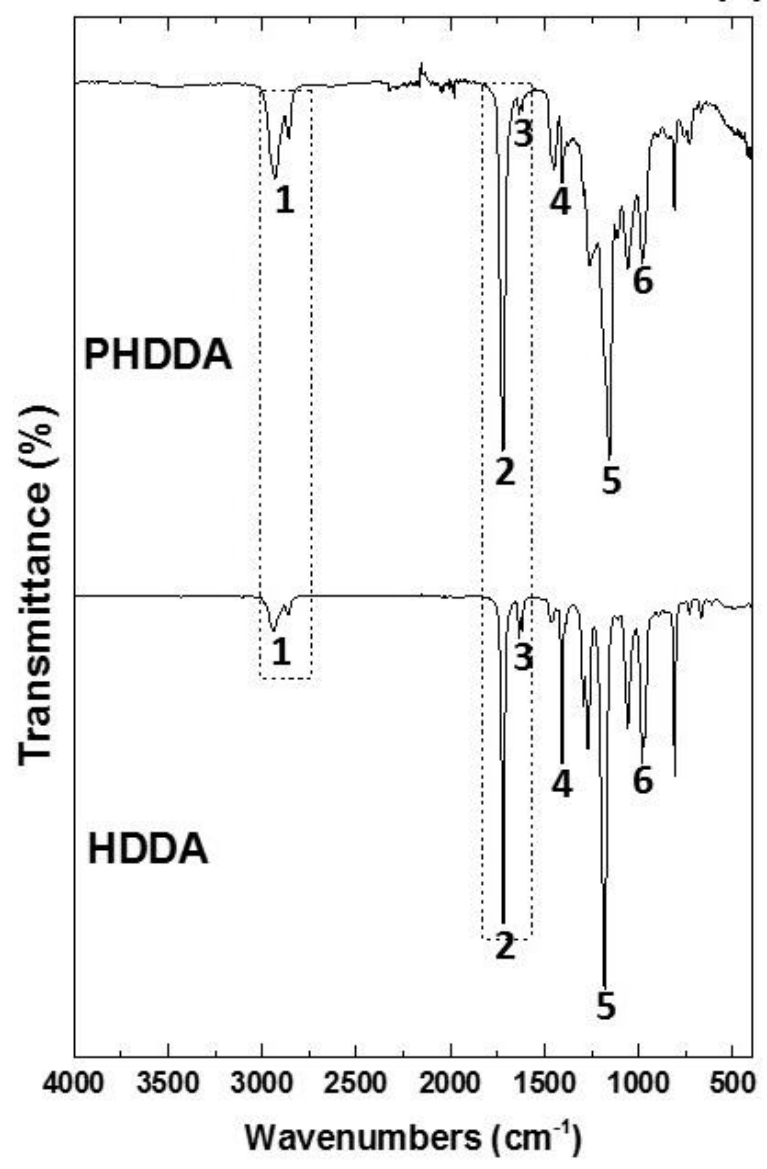

(b) XRD

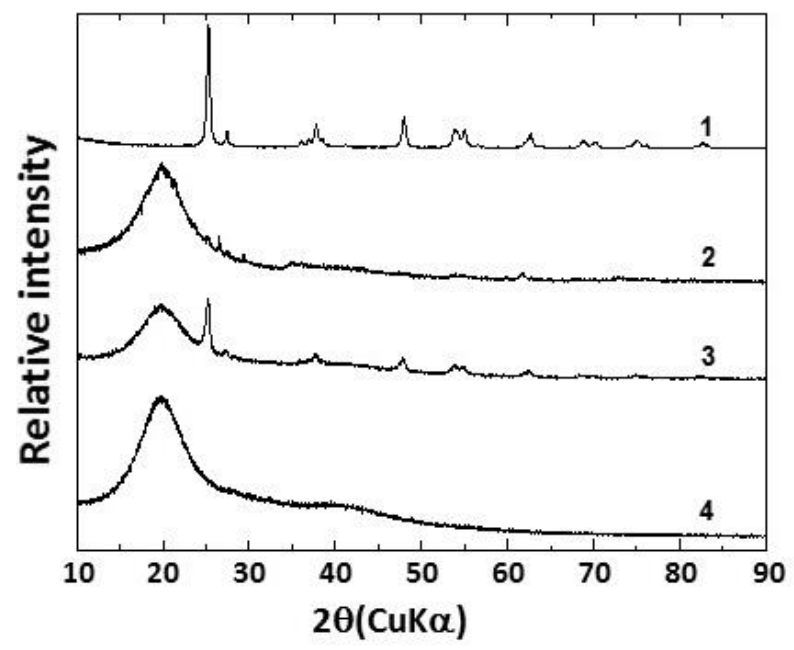

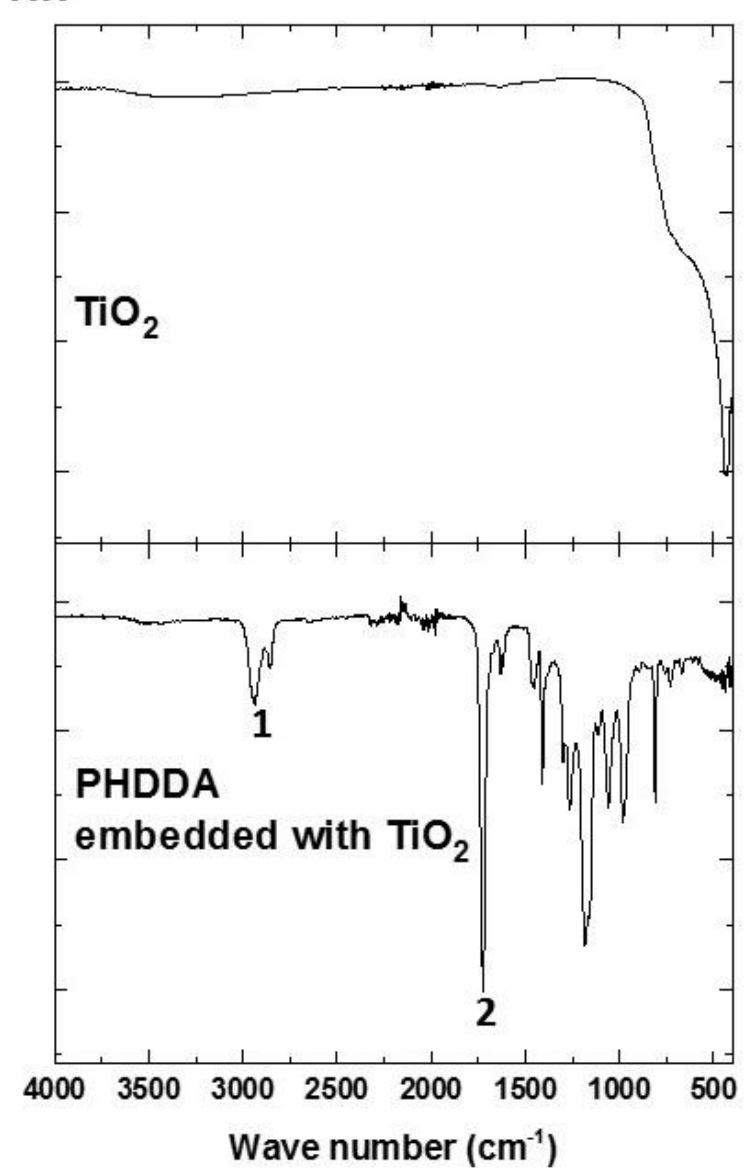

(c) DSC

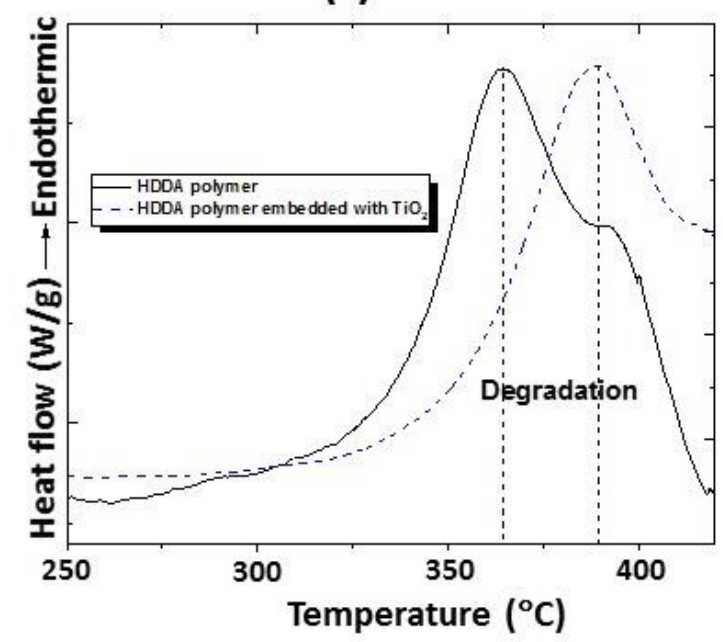

Figure 10. (a) FTIR spectra correlate absorbance versus wave number of: HDDA, pure PHDDA, $\mathrm{TiO}_{2}$ embedded in PHDDA, and pure $\mathrm{TiO}_{2}$; (b) X-Ray diffractograms of: (1) pure $\mathrm{TiO}_{2}$; (2) $\mathrm{TiO}_{2}$ embedded in PHDDA; (3) Physical mixture of $\mathrm{TiO}_{2}$ and PHDDA; (4) Pure PHDDA; (c) Overlay of differential scanning calorimetry (DSC) thermal profiles of pure PHDDA (solid line) and PHDDA embedded with $\mathrm{TiO}_{2}$ (dashed line) in nitrogen atmosphere. 
DSC. The DSC results in nitrogen for the pure polymer and the polymer embedded with $\mathrm{TiO}_{2}$ are shown in Fig. 10 (c). The DSC curve of pure poly(HDDA) exhibited a large endothermic peak at $364{ }^{\circ} \mathrm{C}$ corresponding to thermal degradation of the polymer via depolymerisation and random chain scission. Thermal degradation of polymers in inert atmosphere usually yields an endothermic peak, while an exothermic peak occurs during oxidative degradation in air. ${ }^{65}$ The thermal degradation temperature of the polymer composite was shifted to $389{ }^{\circ} \mathrm{C}$. $\mathrm{TiO}_{2}$ particles have a higher thermal conductivity and heat capacity than the polymer and thus act as heat sink, absorbing heat from the polymer matrix and delaying degradation reactions. Similarly, Liufu et al. ${ }^{66}$ found that the thermal degradation temperature of ethyl methacrylate / ethyl acrylate copolymer was higher by $15^{\circ} \mathrm{C}$ when $\mathrm{ZnO}$ was incorporated in the polymer matrix.

\section{Photocatalytic activity test}

The photocatalytic activity of microspheres loaded with $\mathrm{TiO}_{2}$ was estimated by degradation of MB from aqueous solution under UV light. A steady decrease in the absorbance of MB at the wavelength of maximum absorbance $(664 \mathrm{~nm})$ was observed (Fig. S4a). Two control experiments with the photocatalyst in the dark and without the photocatalyst but under UV light were also carried out (Fig. 11a). The efficiency of MB degradation was calculated as:

$$
M B \text { degradation efficiency }(\%)=\left[\left(C_{o}-C_{t}\right) / C_{o}\right] \times 100
$$

where $C_{o}=1 \mathrm{ppm}$ is the initial concentration of $\mathrm{MB}$ and $C_{t}$ is the concentration of $\mathrm{MB}$ at any time. The control experiment in the dark showed that MB could not be degraded without UV light even in the presence of the particles (Fig. 11a and S4b). Small amount of MB was removed by the particles in the dark, mainly within the first hour, which can be attributed to the physical adsorption (physisorption) of MB onto the particle surface. ${ }^{67}$ No significant degradation by UV 
light in the absence of photocatalyst was observed either (less than $5 \%$ after $9 \mathrm{~h}$ of irradiation). Therefore, the impact of self-degradation (photolysis) of MB could be ignored. Under UV light, the fabricated microspheres degraded about $80 \%$ of MB in 9 h. The results shown in Fig. 10a confirm that MB degradation was dominated by photocatalysis over physisorption or photolysis. The photocatalytic activity of the microspheres was low compared to the results obtained using other composite materials, ${ }^{68}$ probably due to low loading of $\mathrm{TiO}_{2}$ in the microspheres.

The produced particles could easily be recovered and reused, which is an important feature for industrial application. ${ }^{69}$ As shown in Fig. S5, the encapsulated $\mathrm{TiO}_{2}$ can be separated from the treated water by gravitational sedimentation once stirring was stopped. On the other hand, nonencapsulated $\mathrm{TiO}_{2}$ nanoparticles remained suspended in water due to their very low primary size of $20 \mathrm{~nm}$. To check recyclability of encapsulated $\mathrm{TiO}_{2}$, the used microspheres were collected after each cycle, washed with distilled water and acetone and left to dry in the air. The recovered particles were then mixed again with the fresh dye solution of the same initial concentration (1 ppm) and irradiated by UV light for six hours. The absorption spectra of the samples were recorded after each cycle. As shown in Fig. 11 (b), nearly the same degradation efficiency of MB was achieved in each cycle: $65.1 \%, 65.3 \%, 66 \%, 65.5 \%$. These results reveal that polymer particles embedded with $\mathrm{TiO}_{2}$ can be used as an efficient recyclable photocatalyst. 

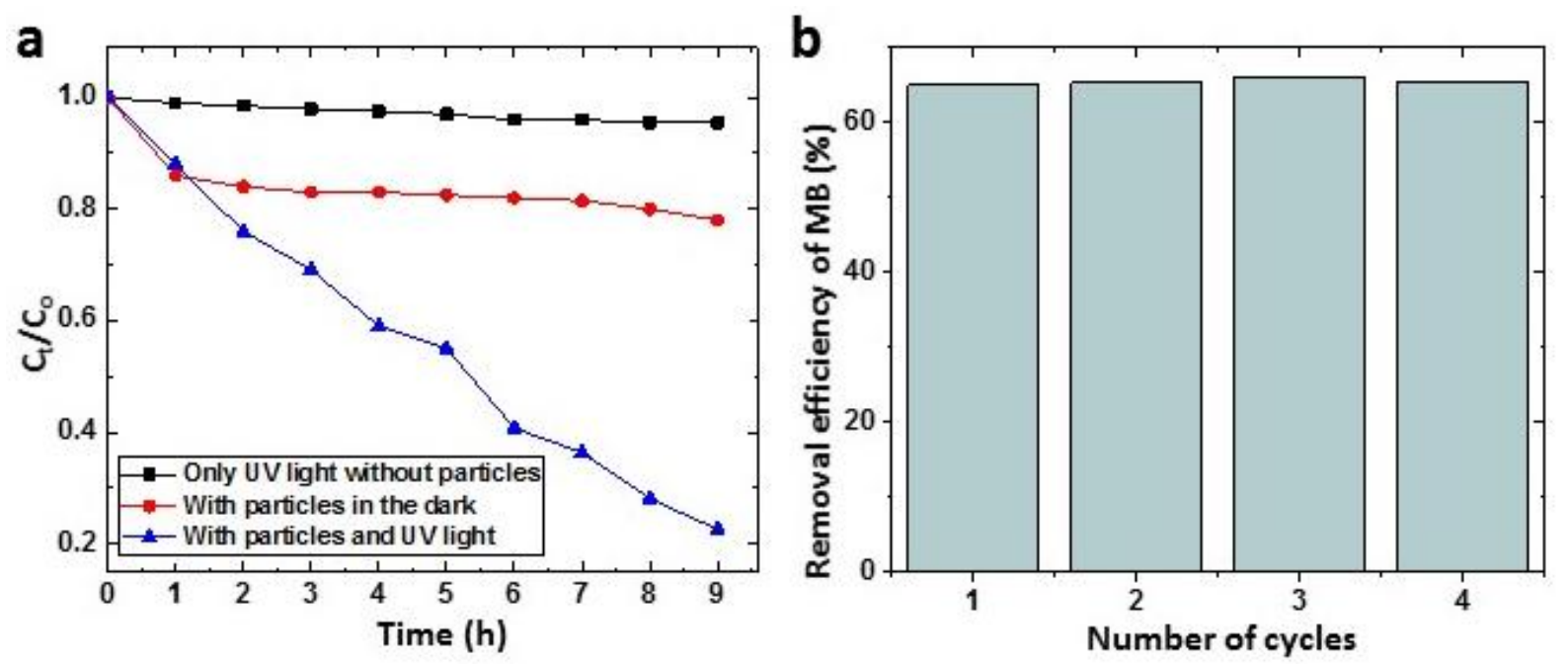

Figure 11. (a) Photocatalytic degradation of MB under UV irradiation in the presence of the produced composite microspheres (photocatalyst/UV) and the two control experiments (no photocatalyst/UV and photocatalyst/no UV); (b) The efficiency of photodegradation of MB after $6 \mathrm{~h}$ under UV light in the presence of the composite microspheres and over four cycles. The average degradation efficiency was $65.4 \%$ with relative standard deviation of $0.43 \%$.

When $10 \mathrm{mg}$ of pure $\mathrm{TiO}_{2}$ nanoparticles were added into $80 \mathrm{~mL}$ of $1 \mathrm{ppm}$ solution of methylene blue, the dye degradation efficiency under the same UV irradiation was 40, 85 and $100 \%$ after 30, 60 and 90 min of photocatalysis, respectively.

\section{Conclusion}

Novel monodispersed poly(HDDA)/ $\mathrm{TiO}_{2}$ microspheres with controlled size and internal morphology comprised of $0.5 \mathrm{wt} \% \mathrm{TiO}_{2}$ embedded in a poly(HDDA) matrix were fabricated by microfluidic emulsification and on-the-fly photopolymerisation. The inclusion of $\mathrm{TiO}_{2}$ increased the thermal degradation temperature of the polymer by $25^{\circ} \mathrm{C}$. The produced microspheres achieved a photocatalytic degradation of methylene blue under UV light and could easily be recycled without any deterioration of the catalytic activity. 
Microcapsules consisted of aqueous cores embedded within a composite polymer matrix were also prepared. The entrapment efficiency of $100 \%$ was achieved when calcein was added in the core liquid. The shell thickness and the number of cores were controlled by varying the fluid flow rates during drop generation, which allowed to adjust the loading capacity of the microcapsules and their UV protection ability and mechanical stability. The capability to uniformly embed $\mathrm{TiO}_{2}$ nanoparticles within the polymeric shell opens up exciting possibilities for manufacturing bifunctional microparticles in which core and shell regions are associated with different functionalities. For instance, the polymer shell can serve for sensing chemical cues in the external solution or UV shielding, whereas the core region can be used for the storage of UVsensitive or volatile materials. The release of encapsulated material can be triggered by rubbing the capsules. The capsules can also be loaded with phase change materials and used for thermal energy storage.

\section{ASSOCIATED CONTENT}

\section{Supporting Information}

The following files are available free of charge.

Figures S1-S6 (PDF).

\section{AUTHOR INFORMATION}

\section{Corresponding author}

*Tel.: +44 1509 222518. E-mail address: g.vladisavljevic@lboro.ac.uk (G.T. Vladisavljević).

\section{Author Contributions}


R.A.N. and G.T.V. conceived and designed the experiments. R.A.N. performed the experiments.

R.A.N., G.T.V. and G.B. analysed the data. All authors contributed in writing the paper.

\section{Funding Sources}

Ruqaiya Al Nuumani holds a scholarship from 'The Government of Oman'. The authors also acknowledge the financial support received from the EPSRC grant EP/HO29923/1.

\section{ACKNOWLEDGMENT}

The authors acknowledge use of facilities within the Loughborough Materials Characterisation Centre.

\section{REFERENCES}

(1) Shchukin, D. G.; Sukhorukov, G. B.; Möhwald, H. Smart Inorganic/organic Nanocomposite Hollow Microcapsules. Angew. Chemie Int. Ed. 2003, 42 (37), 44724475.

(2) Radtchenko, I. L.; Sukhorukov, G. B.; Gaponik, N.; Kornowski, A.; Rogach, A. L.; Möhwald, H. Core-Shell Structures Formed by the Solvent- Controlled Precipitation of Luminescent CdTe Nanocrystals on Latex Spheres. Adv. Mater. 2001, 13 (2), 1684.

(3) Lee, I. S.; Lee, J. Y.; Sung, J. H.; Choi, H. J. Synthesis and Electrorheological Characteristics of Polyaniline-Titanium Dioxide Hybrid Suspension. Synth. Met. 2005, $152(1-3), 173-176$.

(4) Bizdoaca, E. L.; Spasova, M.; Farle, M.; Hilgendorf, M.; Caruso, F. Magnetically Directed Self-Assembly of Submicron Spheres with a $\mathrm{Fe}_{3} \mathrm{O}_{4}$ Nanoparticle Shell. J. Magn. Magn. Mater. 2002, 240 (1), 44-46. 
(5) Schadler, L. S. Polymer-Based and Polymer-Filled Nanocomposites. In Nanocomposite Science and Technology; Wiley-VCH Verlag GmbH \& Co. KGaA, 2004; pp 77-153.

(6) Wright, M.; Uddin, A. Organic_-inorganic Hybrid Solar Cells: A Comparative Review. Sol. Energy Mater. Sol. Cells 2012, 107, 87-111.

(7) Demina, P. A.; Grigoriev, D. O.; Kuz'micheva, G. M.; Bukreeva, T. V. Preparation of Pickering-Emulsion-Based Capsules with Shells Composed of Titanium Dioxide Nanoparticles and Polyelectrolyte Layers. Colloid J. 2017, 79 (2), 198-203.

(8) Sorrentino, A.; Gorrasi, G.; Vittoria, V. Potential Perspectives of Bio-Nanocomposites for Food Packaging Applications. Trends Food Sci. Technol. 2007, 18 (2), 84-95.

(9) Zhu, Y.; Zhao, Y.; Ma, Y.; Deng, M.; Wang, L. Multifunctional Organic-Inorganic Composite Luminescent Nanospheres. Luminescence 2012, 27 (1), 74-79.

(10) Gulyaev, Y. V; Cherepenin, V. A.; Vdovin, V. A.; Taranov, I. V; Sukhorukov, G. B.; Gorin, D. A.; Khomutov, G. B. Decapsulation of Polyelectrolyte Nanocomposite Microcapsules by Pulsed Microwave Effect. J. Commun. Technol. Electron. 2015, 60 (11), 1286-1290.

(11) Timin, A. S.; Gao, H.; Voronin, D. V.; Gorin, D. A.; Sukhorukov, G. B. Inorganic/organic Multilayer Capsule Composition for Improved Functionality and External Triggering. Adv. Mater. Interfaces 2017, 4 (1), 1600338.

(12) Chong, M. N.; Jin, B.; Chow, C. W. K.; Saint, C. Recent Developments in Photocatalytic Water Treatment Technology: A Review. Water Res. 2010, 44 (10), 2997-3027.

(13) Gaya, U. I.; Abdullah, A. H. Heterogeneous Photocatalytic Degradation of Organic 
Contaminants over Titanium Dioxide: A Review of Fundamentals, Progress and Problems. J. Photochem. Photobiol. C Photochem. Rev. 2008, 9 (1), 1-12.

(14) Gupta, S. M.; Tripathi, M. A Review of $\mathrm{TiO}_{2}$ Nanoparticles. Chinese Sci. Bull. 2011, 56 (16), 1639-1657.

(15) Lin, H.; Xu, Z.; Wang, X.; Long, J.; Su, W.; Fu, X.; Lin, Q. Photocatalytic and Antibacterial Properties of Medical-Grade PVC Material Coated with $\mathrm{TiO}_{2}$ Film. J. Biomed. Mater. Res. Part B Appl. Biomater. 2008, 87 (2), 425-431.

Du, J.; Sun, H. Polymer/TiO2 Hybrid Vesicles for Excellent UV Screening and Effective Encapsulation of Antioxidant Agents. ACS Appl. Mater. Interfaces 2014, 6 (16), 1353513541.

(17) Herrmann, J. M.. Heterogeneous Photocatalysis: Fundamentals and Applications to the Removal of Various Types of Aqueous Pollutants. Catal. Today 1999, 53 (1), 115-129.

(18) Xiao, J.; Chen, W.; Wang, F.; Du, J. Polymer/TiO 2 Hybrid Nanoparticles with Highly Effective UV Screening but Eliminated Photocatalytic Activity. Macromolecules 2013, 46 (2), 375-383.

(19) Braun, J. H.; Baidins, A.; Marganski, R. E. TiO2 Pigment Technology: A Review. Prog. Org. Coatings 1992, 20 (2), 105-138.

(20) Kim, M. K.; Kim, C. A.; Ahn, S. D.; Kang, S. R.; Suh, K. S. Density Compatibility of Encapsulation of White Inorganic $\mathrm{TiO}_{2}$ Particles Using Dispersion Polymerization Technique for Electrophoretic Display. Synth. Met. 2004, 146 (2), 197-199.

(21) Chawengkijwanich, C.; Hayata, Y. Development of $\mathrm{TiO}_{2}$ powder-Coated Food Packaging 
Film and Its Ability to Inactivate Escherichia Coli in Vitro and in Actual Tests. Int. J. Food Microbiol. 2008, 123 (3), 288-292.

(22) Jacobs, J. F.; van de Poel, I.; Osseweijer, P. Sunscreens with Titanium Dioxide $\left(\mathrm{TiO}_{2}\right)$ Nano-Particles: A Societal Experiment. Nanoethics 2010, 4 (2), 103-113.

(23) Fei Yin, Z.; Wu, L.; Gui Yang, H.; Hua Su, Y. Recent Progress in Biomedical Applications of Titanium Dioxide. Phys. Chem. Chem. Phys. 2013, 15 (14), 4844-4858.

(24) Nawi, M. A.; Zain, S. M. Enhancing the Surface Properties of the Immobilized Degussa P-25 $\mathrm{TiO}_{2}$ for the Efficient Photocatalytic Removal of Methylene Blue from Aqueous Solution. Appl. Surf. Sci. 2012, 258 (16), 6148-6157.

(25) Campardelli, R.; Della Porta, G.; Gomez, V.; Irusta, S.; Reverchon, E.; Santamaria, J. Encapsulation of Titanium Dioxide Nanoparticles in PLA Microspheres Using Supercritical Emulsion Extraction to Produce Bactericidal Nanocomposites. $J$. Nanoparticle Res. 2013, 15 (10), 1987.

(26) Chowdhury, D.; Paul, A.; Chattopadhyay, A. Photocatalytic Polypyrrole- $\mathrm{TiO}_{2}$ Nanoparticles Composite Thin Film Generated at the Air-Water Interface. Langmuir 2005, $21(9), 4123-4128$.

(27) Gilmour, C. R.; Ray, A.; Zhu, J.; Ray, M. B. Photocatalytic Performance of Titanium Dioxide Thin Films from Polymer-Encapsulated Titania. Ind. Eng. Chem. Res. 2013, 52 (50), 17800-17811.

(28) Shah, S. N. A.; Shah, Z.; Hussain, M.; Khan, M. Hazardous Effects of Titanium Dioxide Nanoparticles in Ecosystem. Bioinorg. Chem. Appl. 2017, 20174101735. 
(29) Wolf, C.; Angellier-Coussy, H.; Gontard, N.; Doghieri, F.; Guillard, V. How the Shape of Fillers Affects the Barrier Properties of Polymer/Non-porous Particles Nanocomposites: A Review. J. Membr. Sci. 2018, 556, 393-418.

(30) Al-Ghamdi, G. H.; Sudol, E. D.; Dimonie, V. L.; El-Aasser, M. S. Encapsulation of Titanium Dioxide in Styrene/n-Butyl Acrylate Copolymer by Miniemulsion Polymerization. J. Appl. Polym. Sci. 2006, 101 (5), 3479-3486.

(31) Yu, D. G.; An, J. H.; Bae, J. Y.; Lee, Y. E.; Ahn, S. D.; Kang, S. Y.; Suh, K. S. Preparation and Characterization of Titanium Dioxide Core/polymer Shell Hybrid Composite Particles Prepared by Emulsion Polymerization. J. Appl. Polym. Sci. 2004, 92 (5), 2970-2975.

(32) Park, B. J.; Sung, J.; Kim, K.; Chin, I.; Choi, H. Preparation and Characterization of Poly(methyl Methacrylate) Coated $\mathrm{TiO}_{2}$ Nanoparticles. J. Macromol. Sci. Part B Phys. 2006, 45 (1), 53-60.

(33) Supsakulchai, A.; Ma, G. H.; Nagai, M.; Omi, S. Preparation of Uniform Titanium Dioxide $\left(\mathrm{TiO}_{2}\right)$ Polystyrenebased Composite Particles Using the Glass Membrane Emulsification Process with a Subsequent Suspension Polymerization. J. Microencapsul. 2003, $20(1), 1-18$.

(34) Supsakulchai, A.; Ma, G. H.; Nagai, M.; Omi, S. Uniform Titanium Dioxide $\left(\mathrm{TiO}_{2}\right)$ Microcapsules Prepared by Glass Membrane Emulsification with Subsequent Solvent Evaporation. J. Microencapsul. 2002, 19 (4), 425-449.

(35) Tang, G.; Li, W.; Cao, X.; Dong, H. In situ microfluidic fabrication of multi-shape inorganic/organic hybrid particles with controllable surface texture and porous internal 
structure. RSC Adv. 2015, 5, 12872-12878.

(36) Eun, T. H.; Kim, S. H.; Jeong, W. J.; Jeon, S. J.; Kim, S. H.; Yang, S. M. Single-Step Fabrication of Monodisperse $\mathrm{TiO}_{2}$ Hollow Spheres with Embedded Nanoparticles in Microfluidic Devices. Chem. Mater. 2009, 21 (2), 201-203.

(37) Nabavi, S. A.; Vladisavljević, G. T.; Gu, S.; Manović, V. Semipermeable Elastic Microcapsules for Gas Capture and Sensing. Langmuir 2016, 32 (38), 9826-9835.

(38) Utada, A. S.; Lorenceau, E.; Link, D. R.; Kaplan, P. D.; Stone, H. A.; Weitz, D. A. Monodisperse Double Emulsions Generated from a Microcapillary Device. Science 2005, 308 (5721), 537-541.

(39) Vladisavljević, G. T.; Al Nuumani, R.; Nabavi, S. A. Microfluidic Production of Multiple Emulsions. Micromachines 2017, 8 (3), 1-34.

(40) Li, X.; Iwai, K.; Pirmoradi, F. N.; Yang, C.; Lin, L. Controlled Drug Delivery via Remotely Heated Core-Shell Magnetic Microcapsules. In Solid-State Sensors, Actuators and Microsystems (TRANSDUCERS), 2015 Transducers-2015 18th International Conference; 2015; pp 1049-1052.

(41) Gao, F.; Wang, X.; Wu, D. Design and Fabrication of Bifunctional Microcapsules for Solar Thermal Energy Storage and Solar Photocatalysis by Encapsulating Paraffin Phase Change Material into Cuprous Oxide. Sol. Energy Mater. Sol. Cells 2017, 168, 146-164.

(42) Chinnayelka, S.; McShane, M. J. Glucose Sensors Based on Microcapsules Containing an Orange/red Competitive Binding Resonance Energy Transfer Assay. Diabetes Technol. Ther. 2006, 8 (3), 269-278. 
(43) Am Kim, C.; Joung, M. J.; Ahn, S. D.; Kim, G. H.; Kang, S. Y.; You, I. K.; Oh, J.; Myoung, H. J.; Baek, K. H.; Suh, K. S. Microcapsules as an Electronic Ink to Fabricate Color Electrophoretic Displays. Synth. Met. 2005, 151 (3), 181-185.

(44) Hu, Y.; Wang, J.; Wang, H.; Wang, Q.; Zhu, J.; Yang, Y. Microfluidic Fabrication and Thermoreversible Response of Core/shell Photonic Crystalline Microspheres Based on Deformable Nanogels. Langmuir 2012, 28 (49), 17186-17192.

(45) Li, J.; Lindley-Start, J.; Porch, A.; Barrow, D. Continuous and Scalable Polymer Capsule Processing for Inertial Fusion Energy Target Shell Fabrication Using Droplet Microfluidics. Sci. Rep. 2017, 7 (1), 6302.

(46) Whelehan, M.; von Stockar, U.; Marison, I. W. Removal of Pharmaceuticals from Water: Using Liquid-Core Microcapsules as a Novel Approach. Water Res. 2010, 44 (7), 23142324.

(47) Zhao, J.; Yang, Y.; Li, Y.; Zhao, L.; Wang, H.; Song, G.; Tang, G. Microencapsulated Phase Change Materials with $\mathrm{TiO}_{2}$-Doped PMMA Shell for Thermal Energy Storage and UV-Shielding. Sol. Energy Mater. Sol. Cells 2017, 168, 62-68.

(48) Decker, C. Photoinitiated Crosslinking Polymerisation. Prog. Polym. Sci 1996, 21 (4), 593-650.

(49) Nabavi, S. A.; Vladisavljević, G. T.; Bandulasena, M. V., Arjmandi-Tash, O.; Manović, V. Prediction and Control of Drop Formation Modes in Microfluidic Generation of Double Emulsions by Single-Step Emulsification. J. Colloid Interf. Sci. 2017, 505, $315-324$. 
(50) Steegmans, M. L. J.; Schroën, C. G. P. H.; Boom, R. M. Generalised Insights in Droplet Formation at T-Junctions through Statistical Analysis. Chem. Eng. Sci. 2009, 64 (13), $3042-3050$.

(51) Vladisavljević, G. T.; Duncanson, W. J.; Shum, H. C.; Weitz, D. A. Emulsion Templating of Poly(lactic Acid) Particles: Droplet Formation Behavior. Langmuir 2012, 28 (36), $12948-12954$.

(52) Gañán-Calvo, A. M.; Gordillo, J. M. Perfectly Monodisperse Microbubbling by Capillary Flow Focusing. Phys. Rev. Lett. 2001, 87 (27), 274501.

(53) Garstecki, P.; Gañán-Calvo, A. M.; Whitesides, G. M. Formation of Bubbles and Droplets in Microfluidic Systems. Bull. Polish Acad. Sci. 2005, 53 (4), 361-372.

(54) Nabavi, S. A.; Vladisavljević, G. T.; Gu, S.; Ekanem, E. E. Double Emulsion Production in Glass Capillary Microfluidic Device: Parametric Investigation of Droplet Generation Behaviour. Chem. Eng. Sci. 2017, 130, 183-196.

(55) Tomotika, S. On the Instability of a Cylindrical Thread of a Viscous Liquid Surrounded by Another Viscous Fluid. Proc. R. Soc. London Ser. A, Math. Phys. Eng. Sci. 1935, 150 (870), 322-337.

(56) Nekouei, M.; Vanapalli, S. A. Volume-of-Fluid Simulations in Microfluidic T-Junction Devices: Influence of Viscosity Ratio on Droplet Size. Phys. Fluids 2017, 29 (3), 32007.

(57) Nabavi, S. A.; Vladisavljević, G. T.; Manović, V. Mechanisms and Control of Single-Step Microfluidic Generation of Multi-Core Double Emulsion Droplets. Chem. Eng. J. 2017, $322,140-148$. 
(58) Steeley, K. G.; Kuestermeyer, B.; Stanton, C.; Yu, J.; Morabito, K.; Li, D.; Mello, C.; Calvert, P.; Tripathi, A.; Shapley, N. C. Uniform Polymer Particles Formulated with Ultraviolet Protective Materials for the Protection of UV Sensitive Molecules. Dye. Pigment. 2014, 105, 12-22.

(59) Sanusi, O.; Warzoha, R.; Fleischer, A. S. Energy Storage and Solidification of Paraffin Phase Change Material Embedded with Graphite Nanofibers. Int. J. Heat Mass Transf. 2011, 54 (19-20), 4429-4436.

(60) Wang, J.; Hu, Y.; Deng, R.; Xu, W.; Liu, S.; Liang, R.; Nie, Z.; Zhu, J. Construction of Multifunctional Photonic Crystal Microcapsules with Tunable Shell Structures by Combining Microfluidic and Controlled Photopolymerization. Lab Chip 2012, 12 (16), 2795.

(61) Wu, K. C.; Halloran, J. W. Photopolymerization Monitoring of Ceramic Stereolithography Resins by FTIR Methods. J. Mater. Sci. 2005, 40 (1), 71-76.

(62) Jaleh, B. \& Fakhri, P. Scholar. In Infrared and Fourier transform infrared spectroscopy for nanofillers and their nanocomposites; 2016; pp 112-129.

(63) Nagaraj, S. K.; Shivanna, S.; Subramani, N. K.; Siddaramaiah, H. Revisiting Powder XRay Diffraction Technique: A Powerful Tool to Characterize Polymers and Their Composite Films. Res. Rev. J. Mater. Sci. 2016, 4 (4), 1-5.

(64) Zhao, W.; Ai, Z.; Dai, J.; Zhang, M. Enhanced Photocatalytic Activity for $\mathrm{H}_{2}$ Evolution under Irradiation of UV-Vis Light by Au-Modified Nitrogen-Doped $\mathrm{TiO}_{2}$. PLoS One 2014, $9(8)$, e103671. 
(65) Peterson, J. D.; Vyazovkin, S.; Wight, C. A. Kinetics of the Thermal and ThermoOxidative Degradation of Polystyrene, Polyethylene and Poly(propylene). Macromol. Chem. Phys. 2001, 202 (6), 775-784.

(66) Liufu, S. C.; Xiao, H. N.; Li, Y. P. Thermal Analysis and Degradation Mechanism of polyacrylate/ZnO Nanocomposites. Polym. Degrad. Stab. 2005, 87 (1), 103-110.

(67) Bouanimba, N.; Zouaghi, R.; Laid, N.; Sehili, T. Factors Influencing the Photocatalytic Decolorization of Bromophenol Blue in Aqueous Solution with Different Types of $\mathrm{TiO}_{2}$ as Photocatalysts. Desalination 2011, 275 (1), 224-230.

(68) Ramli, Z. A. C.; Asim, N.; Isahak, W. N. R. W.; Emdadi, Z.; Ahmad-Ludin, N.; Yarmo, M. A.; Sopian, K. Photocatalytic Degradation of Methylene Blue under UV Light Irradiation on Prepared Carbonaceous $\mathrm{TiO}_{2}$. Sci. World J. 2014, 415136.

(69) Uddin, M. T.; Nicolas, Y.; Olivier, C.; Toupance, T.; Servant, L.; Müller, M. M.; Kleebe, H. J.; Ziegler, J.; Jaegermann, W. Nanostructured $\mathrm{SnO}_{2}-\mathrm{ZnO}$ Heterojunction Photocatalysts Showing Enhanced Photocatalytic Activity for the Degradation of Organic Dyes. Inorg. Chem. 2012, 51 (14), 7764-7773. 


\section{TOC Graphics}

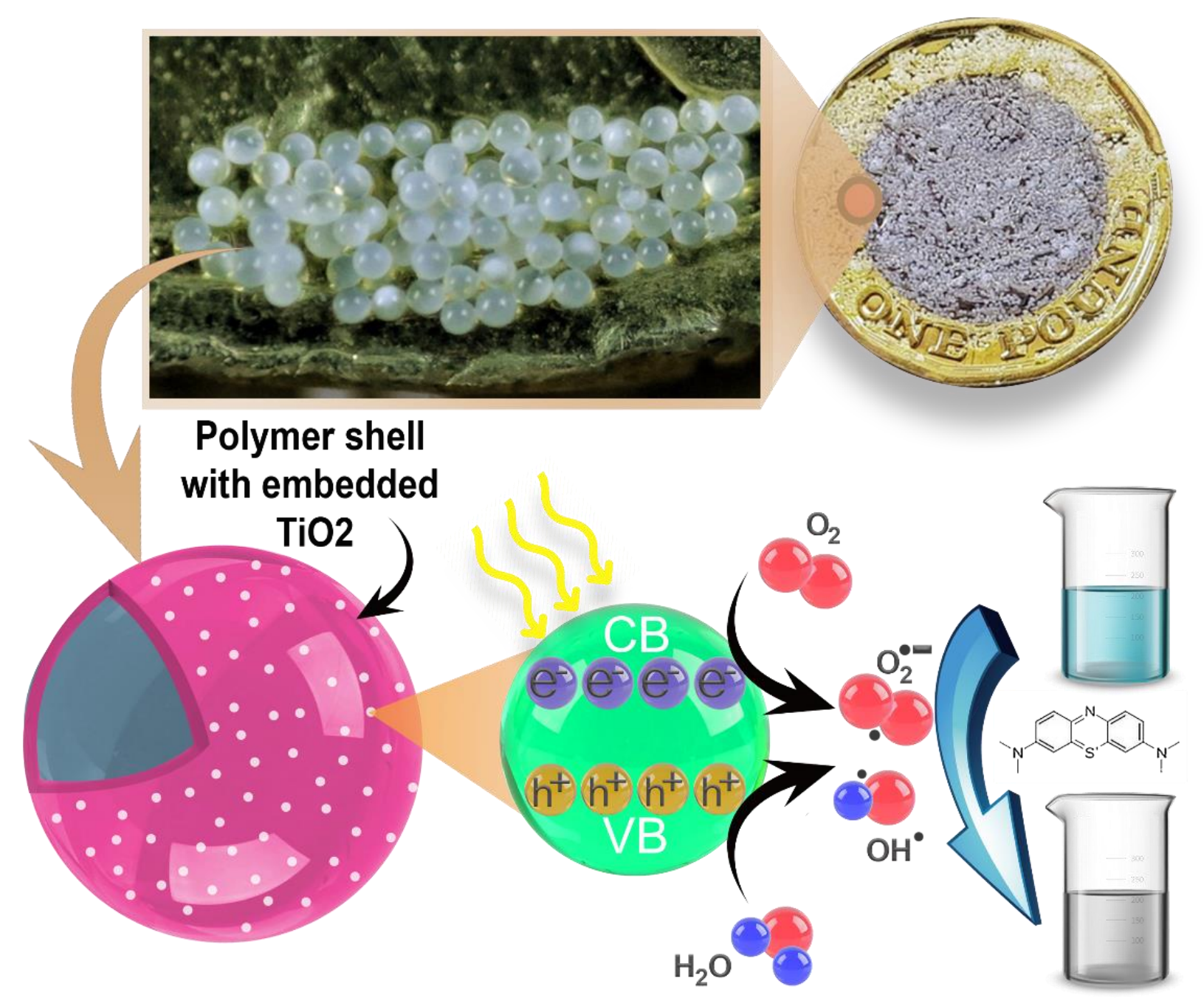

Micrograph of monodispersed poly(1,6-hexanediol diacrylate)-based polymer microcapsules with $\mathrm{TiO}_{2}$ nanoparticles embedded in the shell with high photocatalytic activity and easy separation. 